\title{
LA CRISIS DEL MUNICIPIO LOGROÑES: LOS PRIMEROS PROCESOS DESAMORTIZADORES (1801-1814)
}

\author{
Jesús J. ALONSO CASTROVHEJO*
}

\begin{abstract}
El complejo proceso de la desamortización se va aclarando a medida que se estudian con más detenimiento sus prolegómenos en el XVIII y en los primeros años del XIX. Como dice el autor de este trabajo, sintesis de una de las partes de su tesis doctoral, «los primeros intentos, realizados desde el poder» sirvieron "para adaptar las viejas estructuras tardofeudales a la nueva situación socioeconómica creada por un siglo de acumulación casi ininterrumpida». El caso del municipio logroñés es uno más de los pocos estudiados hasta el momento, pero cobra interés cuando se tiene en cuenta el volumen de enajenaciones realizado en estos prolegómenos a la hora de sacar conclusiones del que luego tendrán las ventas durante el régimen liberal.
\end{abstract}

The study of 'Desamortización' prolegomena -end of the XVIIIth century and beginning of the XIXth-constitutes an important aid for the explanation of that complex process. As the author points out in this résumé of his Doctoral Thesis, "The first attempts made by the establishment (were useful in order to) adapt the old tardofeudal structures to the new socioeconomic situation caused by a century of uninterrupted accumulation».

The case of Logroño is one of the few which have beentreated up to now, but it has an exceptional importance because of the amount of expropiations which took place during those first steps of the process. The comparison between those figures and the sales during the liberal period is significant when drawing conclusions.

\section{Introducción}

Las desamortizaciones de bienes anteriores a la realizada por Mendizábal han suscitado en los últimos años numerosos trabajos que han dado una nueva dimensión y han situado en su verdadera magnitud los primeros intentos, realizados desde el poder, para adaptar las viejas estructuras tardofeudales a la nueva situación socioeco-

* Becario de investigación del I.E.R. 
nómica creada por un siglo de acumulación casi ininterrumpida. Las primeras soluciones adoptadas fueron las de permitir el acceso a la propiedad a una amplia capa no integrada en los grupos privilegiados, pero que contaban con una disponibilidad de capital importante, dispuesto a ser reproducido en aquellas parcelas que permitieran unos beneficios que ya no eran posibles en el campo comercial, debido sobre todo, a la negativa coyuntura europea, que imposibilitaba un comercio entre naciones fluido y seguro ${ }^{1}$.

En este artículo trato de cuantificar el proceso desamortizador llevado a cabo entre 1801 y 1814 en el término municipal de Logroño, desde una doble vertiente: por un lado, el estudio pormenorizado de las ventas realizadas al amparo de la legislación desamortizadora de 1798, y por otro, la venta de bienes del común con que el Ayuntamiento tuvo que hacer frente a una cuantiosa deuda de guerra ${ }^{2}$.

Debo advertir que este trabajo se engloba en el estudio que de la crisis del Antiguo Régimen estoy realizando para mi tesis doctoral bajo la dirección del profesor Gómez Urdáñez. Por ello, si algunos datos se dan por sabidos, o no son suficientemente aclarados en el texto, debe entenderse que son el resultado de otros aspectos de la investigación global, y cuya aclaracion haría demasiado prolijo el trabajo que ahora propongo ${ }^{3}$.

\section{Resultados generales}

El término municipal de Logroño tiene una superficie aproximada de $77 \mathrm{Km} .^{2}$ -40.425 fanegas de tierra-4. De esta superficie estaban en explotación, según el

1. En los últimos años se han publicado numerosos trabajos que estudian detenidamente el fenómeno desamortizador como único objeto de investigación o dentro de la panorámica global de la crisis del Antiguo Régimen en España. Dentro de los primeros pueden citarse: AZAGRA, J.: La desamortización de Godoy en Valencia, (1799-1807). Valencia 1986; o los trabajos de MARCos MARín, A. y PARDO, J. recogidos en el volumen colectivo Desamortización y Hacienda Publica. Madrid 1986, 2 vol. Para Burgos contamos con el trabajo de CuARTAS, M. en la obra colectiva Historia de la ciudad de Burgos Madrid 1985; sin olvidarnos del clásico trabajo de HerR, R. «Hacia el derrumbe del Antiguo Régimen: crisis fiscal y desamortización bajo Carlos IV» en Moneda y Crédito núm. 118. Para una visión global y una bibliografía exhaustiva, Rueda, G.: La desamortización de Mendizábal y Espartero en España. Madrid 1986. Para una exposición clara del marco legislativo: TOMÁS Y VALIENTE, F.: El marco politico de la desamortización en España. Barcelona 1974. HeRR, R., op. cit y FERNÁNDEZ DE PINEDO, E.: «Coyuntura y política económicas» en la obra colectiva Centralismo, Ilustración y Agonía del Antiguo Régimen (1715-1833). Barcelona, 1980.

2. La relación deuda de guerra-venta de bienes municipales ha sido suficientemente probada por FERnÁNDeZ DE PINEDo, E.: «La entrada de la tierra en el circuito comercial: la desamortización en Vascongadas. Planteamientos y primeros resultados» en la obra colectiva Agricultura, comercio colonial y crecimiento económico en la España Contemporánea. Barcelona 1974. Para Vitoria contamos con el completo estudio de ORTIZ DE ORRUÑo, J.M.: Alava durante la invasión napoleónica. Reconversión fiscal y desamortización. Vitoria 1983, donde se da una adecuada bibliografía sobre las ventas de bienes del común durante la guerra de la independencia. También resultan de interés las obras citadas en la nota 1. En La Rioja han tratado este tema GómEZ URDÁÑEZ, J.L., en la obra colectiva Cenicero Histórico, Logroño 1987, págs. 381 y 433, y PASTOR OCÓN, J.L., Transformaciones económicas en Murillo de Río Leza, Tesis de licenciatura inédita, 1986.

3. Las fuentes consultadas para este trabajo son las siguientes: A.H.P. Logroño, sec. Protocolos, cajas $1.133,1.160,1.161,1.163,1.164,1.165$ y 1.180 . Las fuentes parroquiales han sido consultadas en A.C.Lo., cajas años 1806 y 1807 y A. P. Palacio, caja B año 1817. También se han consultado A.H. de Protocolos de Madrid, escribanía de López Fandos, cajas 22.026 a 22.180, ambas inclusive. Para las ventas de bienes del común he utilizado las siguientes fuentes: A.H.P. de Logroño, sec. Protocolos, cajas 1.138 y 1.139 y A.M. de Logroño, Documentos Antiguos, caja 24 exp. 25.

4. Información ofrecida por la Cámara agraria y que coincide con la ofrecida por los peritos en las respuestas generales al interrogario de Catastro de Ensenada. A.H.P., sec. Catastro, voz Logroño, libro de respuestas generales. 
catastro realizado por orden del Marqués de la Ensenada en 1751, 22.484 fanegas repartidas de esta forma:

\section{CUADRO 1}

Superficie cultivada según el catastro de Ensenada. 1751

$\begin{array}{lrr}\text { Regadío } & 7.947 & 35,4 \% \\ \text { Secano } & 6.532 & 29 \% \\ \text { Viñedo } & 7.015 & 31,2 \% \\ \text { Sin labor } & 990 & 4,4 \% \\ & 22.484 & 100 \% 5\end{array}$

La superficie que detentaba el Clero era de 6.905 fanegas, lo que supone el $30,8 \%$ del total, un porcentaje superior a la media nacional ${ }^{6}$. La importancia de las posesiones de la Iglesia es aún mayor al comprobar que el $48 \%$ del total de las tierras de regadío estaba bajo su control, lo que le hace ser el grupo social con una mayor incidencia en la principal fuente de riqueza de la ciudad. La revisión que se realiza en 1770 apenas si hace variar estas cifras?

\subsection{Desamortización de Godoy (1801-1807)}

La desamortización de Godoy afectó, por lo tanto, a unas instituciones eclesiásticas, parroquias y conventos sobre todo, que en el caso logroñés disfrutaban de una parte muy importante de la tierra en explotación, siendo además estas parcelas de una calidad media elevada, según el Catastro de Ensenada ${ }^{8}$.

La cuantificación de las tierras vendidas durante la aplicación de la legislación desamortizadora que en Logroño tuvo siete años de vigencia (1801-1807), presenta algunas dificultades que se deben a la calidad de las fuentes empleadas, ya que en ocasiones esta documentación no recoge la superficie desamortizada, sino solamente la cuantía de la venta y el número de parcelas de que constaban los lotes sacados a subasta. Este hecho afecta principalmente a las ventas realizadas al Marqués de San Nicolás y a las escrituras recogidas en la notaría madrileña de López Fandos.

La conversión en tierra de labor de las compras efectuadas por el Marqués de San Nicolás a la Iglesia parroquial de Santa María de Palacio no presenta ninguna

5. Estas superficies se han obtenido a partir de los libros de lo raiz de seglares y eclesiásticos. A.H.P., sec. Catastro, voz Logroño.

6. Fernández de Pinedo, E., «Coyuntura...» pág. 55 da una cifra que se acerca a $1 / 5$ de la superficie total, para la Iglesia.

7. A.M.Lo., Libros Antiguos (L.A.), núms. 18-23.

8. A.H.P.Logroño, sec. Catastro, voz Logroño, libros de lo raiz de los eclesiásticos, núms. 339, 340, 341. 
dificultad $^{9}$ y los resultados finales, que son los que voy a utilizar como base de este trabajo, nos dan 1.233 fanegas de tierra vendidas en el término municipal de Logroño, lo que representa el $18 \%$ de la tierra de las instituciones eclesiásticas y el $5,5 \%$ de la superficie total cultivada.

La reducción a tierra laborable de la información recogida en la Notaría central de Madrid deja un mayor margen a la hipótesis. Esta fuente aporta nuevas ventas valoradas en 216.286 reales.

Los conventos de los Dominicos y Trinitarios fueron los más afectados, pero conocer la superficie total vendida es una labor casi imposible. Como solución exclusivamente especulativa he optado por dividir el importe de estas ventas por el precio medio de la fanega de tierra, según el remate nominal que aparece en el apéndice $1 \mathrm{y}$ que es de 1.900 reales. Esto nos da una superficie de 120 fanegas, cifra algo inferior a las pérdidas de ambos Conventos si comparamos el catastro de $1770 \mathrm{y}$ el apeo realizado en 1818 :

\author{
CUADRO 2 \\ Superficie de los Conventos de Dominicos y Trinitarios \\ (en fanegas)
}

$\begin{array}{lccc} & 1770 & 1818 & \text { Diferencia } \\ \text { Trinitarios } & 348 & 286 & 62 \\ \text { Dominicos } & 343 & 248 & 95 \\ & & & 15710\end{array}$

El hecho de que no fueran exclusivamente estos conventos los afectados, sino que hubiera otras instituciones de menor importancia que también sufrieron el proceso desamortizador y que ya no aparecen en posteriores catastros hace preferible que para un mayor rigor en la exposición no se tomen en cuenta las cifras aportadas por la escribanía de López Fandos, aceptando como ventas finales 1.233 fanegas de tierra, cantidad que obviamente peca por defecto pero que reúne todas las exigencias de rigor documental ${ }^{11}$.

9. La documentación encontrada en el archivo parroquial de Palacio sólo especifica que se vendieron al Marqués de San Nicolás 125 heredades y 21 casas por un importe de 1.312 .500 reales, pagados integramente en vales. La superficie de 424 fanegas la he deducido de la consulta de dos fuentes distintas. La primera de ellas es el apeo general realizado en 1818 y que otorga al Marqués una superficie de 433 fanegas (A.M.Lo. L.A. núm. 9). El vaciado de las escrituras de compra-venta me permitió comprobar que el Marqués sólo compró tierra durante la desamortización y durante la guerra de la independencia. En esta segunda oportunidad solamente adquirió nueve fanegas, con lo cual en la desamortización compró 424 . Esta cifra es similar a la que obtenemos al multiplicar el número de heredades - 125 - por la superficie media de las parcelas vendidas de la iglesia de Palacio que es de 3 fanegas y 3 celemines. La multiplicación nos da un resultado de 406 fanegas. Por ello asumo para este artículo la primera superficie indicada de 424 fanegas como monto total de las compras realizadas por el Marqués.

10. La revisión de 1770 en A.M.Lo. L.A. número 23 y el apeo de 1818 en L.A. número 10.

11. La superficie aproximada que pudo desamortizarse entre 1801 y 1807 si admitimos las ventas de las que no hay una información detallada, puede situarse en torno a las 1.500 fanegas, cifra escasamente superior a la ofrecida como base de este trabajo y que es la más segura por la fiabilidad de las fuentes empleadas. 


\section{CUADRO 3 \\ Superficie desamortizada entre 1801 y 1807}

(en fanegas)

Superficie cultivada
Superficie del clero
Superficie desamortizada

$\begin{array}{ccc} & & 22.484 \\ & 6.905 & 30,8 \% \\ 1.233 & 18 \% & 5,5 \%\end{array}$

22.484

$5,5 \%$

\subsection{Ventas de bienes del común (1809-1813)}

La cuantificación definitiva de las ventas de bienes del común es más sencilla. Se vendieron 146 parcelas que suponen 954 fanegas de tierra, por un valor final de 1.167.794 reales $^{12}$. La totalidad de la tierra correspondía a la Dehesa de Varea que tenía una superficie de 1.453 fanegas ${ }^{13}$; pero muchas de ellas habían sido roturadas quedando reducida en el momento de su venta a una cabida no muy superior a las 1.000 fanegas $^{14}$. Como resuitado de estas ventas el Ayuntamiento se quedó sin ningún tipo de bien comunal. La consecuencia más visible de estas enajenaciones fue la incapacidad de los sucesivos gobiernos municipales para controlar el gasto público, viviendo siempre a un paso de la bancarrota y con unas clases desposeídas que sufrían la peor parte de un sistema impositivo que ya sólo podía gravar los consumos para intentar equilibrar los presupuestos.

A la vista de estos datos creo que no se debe infravalorar la importancia de las ventas realizadas en este período (1801-1813) pues entre ambas suman 2.187 fanegas, que representa un $10 \%$ de la superficie total de la tierra cultivada en Logroño. Las consecuencias económicas que en una población pequeña, como era Logroño -pues no llegaba a los 7.000 habitantes antes de la Guerra de la Independencia- tuvo este trasvase de propiedad las veremos más adelante cuando estudiemos las personas y grupos que más ampliamente se beneficiaron de las posibilidades de compra que desde las instituciones del poder -ya fuera el Ayuntamiento, ya el Gobierno de la Nación- les ofrecieron.

\section{Análisis de los vendedores}

\subsection{Desamortización de Godoy}

El clero logronés se agrupaba en torno a cinco parroquias y ocho conventos, de los que ya dijo Jovellanos que eran la causa de la ruina del pueblo ${ }^{15}$. Entre todos ellos

12. Apéndice 2.

13. A.H.P. sec. Catastro, voz Logroño respuestas generales.

14. Las roturaciones son difíciles de cuantificar pero una aproximación nos la da la relación que las parroquias logroñesas hacen en 1824 sobre los roturos realizadas para poder cobrar los diezmos. Lo roturado hasta 1814, año en que termina la venta de comunes, se aproxima a las 400 fanegas, sólo en la Dehesa. A.M.Lo Indice cronológico de expedientes (I.C.E.) caja 329.

15. Jovellanos, Diarios, Madrid 1967 pág. 156. 
controlaban al menos el $75 \%$ de la tierra que se encontraba en manos eclesiásticas, siendo el otro $25 \%$ para el clero secular a título individual y otras órdenes sin conventos en la ciudad ${ }^{16}$.

Las parroquias con mayor riqueza eran Santa María de Palacio, Santa María de la Redonda y Santiago el Real. Ellas detraían el diezmo del $90 \%$ de la población y controlaban un tercio del total de las tierras que poseía el clero en Logroño. A las tres les afectó el proceso desamortizador aunque de una manera desigual. Mientras que Santa María de Palacio y Santa María de la Redonda veían sus posesiones reducidas en 1.078 fanegas entre ambas -644 y 434,8 respectivamente- a Santiago el Real solamente se le desamortizaban 11 fanegas de tierra. La razón de esta desigualdad puede deberse a que la parroquia de Santiago generalizó en el último tercio del siglo XVIII un sistema de ventas del dominio útil de la tierra, mientras el Cabildo conservaba el dominio directo de la misma y recibía un canon anual a modo de renta; por el contrario las otras dos parroquias practicaban un sistema de explotación de la tierra que se basaba en el arriendo directo por un período corto de tiempo que nunca superaba los nueve años de duración. A la cuarta parroquia en importancia, San Blas, se le enajenaron 100,4 fanegas de tierra, y a otras pequeñas instituciones se les desamortizaron en total 43 fanegas (Vid Gráfico 1 y Apéndice 1).

El ritmo de ventas no fue uniforme durante los siete años que se mantuvieron en vigor los decretos desamortizadores. En 1801 y 1802 las ventas representaron el 30\% del total, mientras que durante 1803 y 1804 no salió a subasta ni una sola parcela debido a la gravísima crisis que azotó a la ciudad durante esos años. En 1805 se vendieron 11 fanegas, que representan un $0,9 \%$. Una vez superada la crisis y con una mayor presión compradora se enajenaron durante los años 1806 y 1807 el 69\% del total de tierras desamortizadas, hecho que se corresponde con un mayor esfuerzo desamortizador en el resto de la península17 (Gráficos, 2, 3 y 4).

El tipo de tierra que salió a subasta, su calidad y sus rendimientos son factores muy importantes para explicar después el interés de los compradores o su apatía en el momento de la puja. En Logroño el grueso de las ventas lo constituyeron tierras de regadío de una elevada calidad media, con unos rendimientos elevados y cosechas anuales $^{18}$. Las tierras de secano y el viñedo tuvieron una presencia marginal en las subastas. El siguiente cuadro muestra la distribución de la tierra que finalmente se vendió:

16. Vid. nota 8 .

17. AZAGRA, op. citl. pág. 42; HERR, op. cit. págs. 81-89; CuARTAS, op. cit. pág. 514.

18. Si aplicamos a la superficie de regadío vendida los mismos porcentajes de calidad que establece el Catastro de Ensenada para las tierras de la Iglesia obtenemos estos resultados:

$\begin{array}{lrr}\text { Huertas } & 32 \text { fanegas } & 3 \% \\ 1 .^{\mathrm{a}} \text { Clase } & 96 " » & 9 \% \\ 2 .^{\mathrm{a}} " & 545 " & 51 \% \\ 3 .^{\mathrm{a}} " & 395 » & 37 \%\end{array}$




\section{CUADRO 4}

Tipo de tierra desamortizada. 1801-1807

$\begin{array}{lcccc} & \begin{array}{c}\text { Superficie } \\ \text { en Fanegas }\end{array} & \% & \begin{array}{c}\text { Número de } \\ \text { parcelas }\end{array} & \begin{array}{c}\text { Fanegas/ } \\ \text { parcelas }\end{array} \\ \text { Regadío } & 1.068 & 87,5 & 318 & 3 \text { Fan } 4 \text { cel } \\ \text { Secano } & 158 & 12 & 22 & 7 \text { Fan } 2 \text { cel } \\ \text { Viñedo } & 7 & 0,5 & 2 & 3 \text { Fan } 6 \text { cel } \\ \quad \text { Totales } & 1.233 & 100 & 342 & \end{array}$

El que la gran mayoría de la tierra vendida sea de regadío deberá ser considerado también a la hora de relacionar la calidad de la tierra con los precios de tasación y de remate. El tamaño de las parcelas responde casi a la perfección a lo que es la parcela media según el Catastro del Marqués de la Ensenada, que establecía en 3 fanegas y 6 celemines la superficie de las fincas de regadío ${ }^{19}$. Fincas de buena calidad y con una extensión acorde a la que existía en el término municipal son, pues, las principales características de las tierras que se pusieron a subasta entre los años 1801 y 1807 .

El precio que se pagó por toda esta tierra vendida no ha podido ser calculado con la exactitud que hubiera sido deseable; ello es debido a varios factores. El primero es que no hay precio de remate ni de tasación para 59 fanegas de regadío que pertenecían a la Iglesia Colegiata de Santa María de la Redonda. El segundo es que las ventas efectuadas al Marqués de San Nicolás incluyen en el mismo lote fincas rústicas y urbanas y por ello es difícil establecer el precio final que pagó por cada una de las compras que realizó. Sin embargo si utilizamos los precios medios que se pagaron por las fincas de Sta. María de Palacio y los aplicamos a la superficie adquirida por el Marqués, creo que el margen de error será mínimo y podremos ofrecer, por lo tanto unas cifras que se acerquen bastante a los precios que se pagaron en realidad por las fincas vendidas ${ }^{20}$.

Los ingresos contrastados suponen 2.226 .549 reales $^{21}$, a los que hay que sumar los 130.000 reales que aproximadamente costaron las 59 fanegas que están sin tasar y sin precios de remate y los 216.286 reales producto de las ventas sólo halladas en la notaría de López Fandos. Son entonces 2.572.935 reales, la mayoría pagados en vales, los que la Hacienda Real ingresó por concepto de ventas de tierra y a los que habría que añadir los 839.521 reales que ingresó por las ventas de bienes urbanos ${ }^{22}$. Si aceptamos las cifras que da $\mathrm{R}$. Herr ${ }^{23}$ para el total provincial -14.586 .000 reales- las ventas en Logroño supusieron un $22 \%$, porcentaje demasiado elevado y que oscurece

19. Extensión calculada después de la elaboración de los datos extraídos en las respuestas particulares del catastro de Ensenada.

20. El precio medio de las fincas vendidas de la Iglesia de Palacio era de 2.300 reales, que multiplicados por 424 fanegas nos da un precio medio de 975.200 reales.

21. Apéndice 1.

22. La importancia de la desamortización urbana es escasa, sólo se vendieron 45 edificios de un total de 1.400 catastrados.

23. HERR, R., op. cit., pág. 69. 
lo que debió ocurrir en otras zonas de La Rioja. Por lo tanto creo que las cifras que da Herr están consideradas a la baja y el monto total de la desamortización en la provincia es superior. Pero, de todos modos, hasta que no se realicen nuevas investigaciones que cubran las zonas más importantes de la provincia no podemos entrar en una crítica rigurosa de las cifras ofrecidas por Richard Herr.

Desglosados por tipos de cultivos los ingresos obtenidos durante la Desamortización ofrecen este resultado:

CUADRO 5

Ingresos distribuidos según el tipo de cultivo

$\begin{array}{lrcc} & \text { superficie } & \begin{array}{c}\text { precio remate } \\ \text { nominal }\end{array} & \% \text { precio total } \\ \text { Regadío } & 1.009 & 2.163 .496 & 97 \\ \text { Secano } & 158 & 55.030 & 2,5 \\ \text { Viñedo } & 7 & 8.023 & 0,5 \\ \text { Sin pagar } & 59 & - & - \\ \quad \text { Total } & 1.233 & 2.226 .549 & 100\end{array}$

También en este cuadro se ve la importancia abrumadora que el regadío tuvo en el proceso desamortizador, siendo nuevamente las tierras preferidas por los compradores y acaparando casi todo el dinero que salió al mercado.

El estudio de las relaciones que se establecen entre los justiprecios realizados por los peritos y los precios finales que alcanzan las fincas después de la clásica subasta siempre han desvelado importantes aspectos de los procesos desamortizadores, de los compradores y de las calidades de la tierra puesta en venta. Sin embargo las fuentes que he podido manejar decían muy poco sobre las tasaciones y por lo tanto los datos que ahora presento deben ser admitidos con toda clase de reservas porque los casos ponderados son poco significativos. Sólo he utilizado datos referentes a 204 fanegas de regadío y 69,5 de secano. En algunos casos la unión en el mismo remate de tierras de regadío y secano imposibilitaba que esas cifras fueran tomadas en consideración. Tampoco he podido estudiar las relaciones entre superficie en venta y remate, pues todos los contratos de venta hacían referencia a lotes, sin desglosar la tasación y remate individualizada de cada una de las parcelas. Ante tal cúmulo de limitaciones sólo he podido elaborar este cuadro:

CUADRO 6

Valores de tasa y remate

$\begin{array}{lccrrcrc} & \text { Superficie } & \% & \text { tasa } & \begin{array}{c}\text { Remate } \\ \text { Nominal }\end{array} & \% \text { dif. } & \begin{array}{c}\text { Remate } \\ \text { Real }\end{array} & \% \text { dif. } \\ \text { Regadío } & 204 & 19 & 345.750 & 459.820 & +33 & 308.080 & -11 \\ \text { Secano } & 69,5 & 44 & 19.115 & 26.500 & +38,5 & 17.755 & -7\end{array}$


Los remates reales los he obtenido descontando a los precios nominales un 33\%, porcentaje estimado de depreciación de los vales reales con los que se efectuaban la mayoria de los pagos, y que para los casos estudiados en este apartado no ofrece ninguna duda, pues todos los pagos se efectuaron en vales, salvo los pequeños «picos» que nunca suponían más de doscientos reales en metálico ${ }^{24}$.

El conocimiento de los precios que se pagaron por las tierras desamortizadas no nos permite comprender su verdadera significación al no tener elementos de comparación con otras ventas realizadas al margen del proceso desamortizador. Por ello es indispensable establecer la serie de precios anuales que se estaban pagando en el mercado libre de tierras de la ciudad por parcelas de similares características a las desamortizadas 25 , la comparación entre ambas series nos permitirá comprobar la actitud de los compradores y la atracción que sobre ellos podían ofrecer las tierras puestas en subasta. Los resultados pueden observarse en el siguiente cuadro y en el gráfico 5 y se refieren exclusivamente a parcelas de regadío:

\section{CUADRO 7}

Precio de la fanega de tierra en el mercado libre y durante la desamortización

$\begin{array}{cccc}\text { Años } & \begin{array}{c}\text { Mercado } \\ \text { libre }\end{array} & \begin{array}{c}\text { DESAMORTIZACION } \\ \text { Remate } \\ \text { nominal }\end{array} & \begin{array}{c}\text { Remate } \\ \text { real }\end{array} \\ 1801 & 1.360 & 2.254 & 1.510 \\ 1802 & 911 & 2.750 & 1.842 \\ 1803 & 1.490 & - & - \\ 1804 & 877 & - & - \\ 1805 & 1.233 & 2.772 & 1.857 \\ 1806 & 1.359 & 1.823 & (1.221) \\ 1807 & 1.387 & 2.300 & 1.541 \\ \text { Precio Medio } & 1.231 & 2.380 & 1.594\end{array}$

() Valor aproximado pues no se conoce con exactitud lo pagado en vales y en dinero.

Los compradores pagaron precios superiores a los del mercado todos los años salvo, quizás, en 1806, año en que se desamortizaron los bienes de Santa María de la Redonda. Las fuentes consultadas no me han permitido establecer la relación entre remate nominal y remate real. Sólo una escueta noticia «se remataron en menor cuantía de la tasa» ${ }^{26}$, me hace suponer que los pagos se realizaron en su mayoría con vales, pues si no, se hubiera reflejado en la escritura la forma de pago, como sucedía siempre que esta se efectuaba íntegramente en metálico o su proporción era mayor a la de los vales.

24. Para este descuento he seguido a Azagra, J., op. cit. pág. 41 .

25. Datos extraídos del vaciado de todos los protocolos notariales referentes a estos años. A.H.P. sec. protocolos, cajas 1.134-1.137, 1.143, 1.120, 1.160-1.165, 1.177-1.181, 1.193.

26. A.H. Protocolos de Madrid escribanía de López Fandos protocolo 22.178. 
La tierra puesta en venta durante la desamortización se pagó a unos precios más elevados que los que regían en los intercambios normales entre vecinos. Un análisis detallado de los cuadros 6 y 7 nos va a permitir matizar esta afirmación y conocer sus causas.

El justiprecio de la fanega de regadío era de 1.695 reales, tasación sensiblemente superior a los precios que regían en el mercado, quizás por ello no sea tan extraño que los compradores rebajaran los precios ofreciendo unos remates más bajos que los precios de salida, pues el precio final de la fanega se situó en 1.594 reales, cifra más acorde con lo que se pagaba durante esos años por fincas de similares características. Las causas por las cuales los compradores pagaron la fanega a unos precios superiores a los normales no deben achacarse exclusivamente a los altos precios de salida; el raquítico mercado de tierras, que impedía por su especial naturaleza que el juego de la oferta y la demanda fuera más fluido, unido a una fase de acumulación de capitales provenientes en su mayoría del comercio vinícola y que no pudieron encontrar colocación en empresas mercantiles debido a la situación internacional, empujaron a estos incipientes burgueses a invertir en el único bien que en ese momento era aún rentable, la tierra, y que gracias a la política del gobierno salía al mercado en unas condiciones ventajosas para los potenciales compradores, al poder adquirir las fincas con papel que estaba sumamente depreciado.

Una nueva aproximación al tema, en este caso meramente especulativa, es la que se refiere a devaluar también los justiprecios en un 33\%, pues no resulta extraño pensar que las tasaciones pudieran estar sobrevaloradas al conocer que la mayoría de los pagos iban a realizarse con vales reales, ya que uno de los principales motivos de la desamortización era precisamente reducir la deuda que el Estado tenía contraída por la emisión de esos títulos. Por lo tanto, si aplicamos también a los precios de tasa la corrección antes indicada vemos que los precios de salida se acercan mucho a los precios medios que los compradores pagaban en el mercado libre de tierras, pues, en este supuesto, la fanega sale tasada a 1.135 reales. Esta reducción se justificaría también por aquellos casos, escasos pero significativos, en que el pago en metálico conllevaba una disminución del precio de tasa que se podía cuantificar en estas mismas devaluaciones ${ }^{27}$.

Como resumen, destacaré que los precios finales estuvieron por debajo de los de tasación en un $11 \%$, pero que superaron a los que se estaban pagando en los intercambios normales entre vecinos en un $29 \%$, debido ello a dos factores principales: el primero la calidad de la tierra, suficiente como para ser atractiva a los potenciales compradores y el segundo que en Logroño, como en otras zonas del país, se había formado un conglomerado heterogéneo de grupos de diversa procedencia -labradores acomodados, viticultores y comerciantes-, principal beneficiario de la coyuntura alcista del último tercio del siglo XVIII y que para poder continuar en su posición de privilegio necesitaban invertir los capitales acumulados en la anterior etapa, en un momento en que la situación no era la más favorable para empresas de riesgo. En Logroño, la posible inversión de estos capitales en actividades ligadas a la explotación del viñedo se veía también frenada por un retroceso grave de su comercialización hacia el País Vasco principalmente. Por lo tanto, la única salida segura que les quedaba era la tierra y el Gobierno les permitió acceder a ella. 


\subsection{La venta de bienes del común}

La entrada y posterior asentamiento de las tropas francesas en Logroño obligó a realizar a sus habitantes un gasto extraordinario para satisfacer las numerosas demandas galas. Los recursos de los que se valieron los sucesivos Ayuntamientos para hacer frente a las constantes requisas y peticiones del ejército invasor fueron la utilización de la fuerza por los regidores unas veces, y otras la petición de crédito por medio de la emisión de bonos de alcance local, como los que sirvieron para pagar una primera imposición cifrada en algo más de un millón de reales. Para pagar a los vecinos que habían aprontado su dinero, el Ayuntamiento, falto de recursos, se vio obligado a recurrir a los únicos bienes que poseía, las tierras comunales, que para entonces se habían reducido a una única dehesa de algo más de mil fanegas de superficie. De la adopción de esta forma de pagar el crédito no están exentos aquellos prestamistas que ya habían comprado tierras durante la desamortización de Godoy y que ahora encontraron una nueva oportunidad para poder completar sus explotaciones a costa de las dehesas comunales. La venta de estas explotaciones del común se realizó entre 1809 y 1813 en cuatro fases distintas que estudiamos a continuación 28 .

\section{Primera fase}

Se realizó entre 1809 y 1810 . La mecánica de la adjudicación se redujo a subastar las parcelas que previamente habían delimitado dos peritos encargados por el Ayuntamiento de dividir la Dehesa en el mayor número de fincas posibles, siendo conscientes de que sólo esos terrenos ofrecían algún atractivo a los numerosos acreedores. Para el pago se exigía que se entregaran solamente bonos emitidos por el Ayuntamiento y que estuvieran a nombre del comprador, intentando así evitar la especulación que con esos títulos pudieran hacer inversores sin escrúpulos. Cuando el importe de los bonos no cubría una puja el comprador podía completarla con dinero en efectivo. Sin embargo, algunos especuladores se dedicaron a comprar bonos de pequeñas cantidades para después acceder a las subastas. A pesar de estar prohibido, los comisionados del Ayuntamiento legalizaron también este tipo de venta fraudulen$\mathrm{ta}^{29}$.

El cuadro resumen de esta primera etapa de la enajenación es el siguiente:

\section{CUADRO 8}

Primera fase de las ventas de tierras del común

$\begin{array}{cccccccc}\text { Años } & \text { comp. } & \text { parc. } & \% & \text { Fan. } & \% & \text { Importe } & \text { Débito del A. } \\ 1809-10 & 40 & 79 & 54 & 281 & 30 & 479.060 & 500.788\end{array}$

28. Sobrón ElgueA, M.C., Logroño en la guerra de la Independencia. Logroño 1987. Esta autora realiza un encomiable esfuerzo de cuantificación del gasto, durante todo el período bélico.

29. A.H.P. sec. protocolos caja 1.138. Un ejemplo de esto último es el de Julián Muro, comerciante, que compró pagarés a pequeños labradores y pudo así adquirir 19 fanegas. Más normal era la unión de varios individuos para pujar por las parcelas que les interesaban. 
La extensión de las parcelas se acerca a la media ya vista para la desamortización de Godoy, pues es de 3 fanegas y 6 celemines. Sin embargo hay que hacer algunas matizaciones a estas cifras. La primera de ellas es que se trataba de tierras vírgenes, sin roturar, lo que suponía una compra que no iba a ofrecer una rentabilidad inmediata. Pero la posibilidad de que los prestamistas perdieran su dinero, les impulsó a participar en estas ventas, que de alguna forma ellos mismos habían provocado con sus continuas presiones sobre el Ayuntamiento para que éste se responsabilizara de las deudas ocasionadas por la invasión francesa.

La posibilidad de perder el dinero prestado empujó a los posibles compradores a pujar alto por las fincas, acercándose siempre el remate más a las cantidades que tenían en bonos que a los precios de salida; por ello creo que no tiene interés estudiar las relaciones entre tasación y remate, pues el apéndice 2 es suficientemente explícito de lo anteriormente expuesto.

Estas primeras ventas se definen también por el hecho de que las condiciones impuestas por el Ayuntamiento para los pagos, impidieron a los pequeños campesinos y artesanos acceder a la propiedad de alguna de las parcelas en venta. Estos grupos, acreedores de pequeñas cantidades, tuvieron que vender sus bonos si no querían perder el dinero adelantado y fueron los comerciantes con liquidez quienes más se aprovecharon de las facilidades concedidas a estos grupos por los comisionados de las enajenaciones. Las protestas por este tipo de subasta no se hicieron esperar, pero paradójicamente fueron los sectores más privilegiados quienes intentaron cambiar el sistema de adjudicaciones. Cesáreo Antonio Benito del Valle, hacendado local, ex regidor perpetuo, ganadero y con secaderos de lana en Canales de la Sierra, fue el primero que protestó por la intromisión de los especuladores de bonos:

«Pero no pocas veces acaece quedar las fincas en sujeto que guardo su dinero o dio poco cuando la ciudad lo necesitaba y lo saca para emplearlo en su privativo beneficio quedandose el que alargo sus efectos y dinero en pro del vecindario sin el pago y $\sin$ las fincas» ${ }^{30}$.

Con esta denuncia no pretendía que se evitaran ese tipo de abusos, sino que los comisionados variaran sus criterios de parcelación para permitirle a él acceder a una finca de 33 fanegas en una sola parcela, cosa que finalmente consiguió.

\section{Segunda fase}

Como quiera que el Ayuntamiento no había conseguido pagar a todos sus acreedores puso en venta nuevas tierras. Esta vez se trataba de zonas ya roturadas y en explotación, lo que permitió al Ayuntamiento imponer dos condiciones a los posibles compradores. La primera de ellas es que se debía pagar la mitad en bonos y la otra mitad en metálico y la segunda que los futuros propietarios tenían que aceptar los contratos de arrendamiento vigentes por un período de tres años, pasados los cuales serían propietarios plenos de las parcelas compradas.

Este segundo tipo de subasta tuvo unas repercusiones mucho menores, que se pueden resumir en este cuadro: 


\author{
CUADRO 9 \\ Segunda fase de las ventas de tierras del común
}

$\begin{array}{lccccccc}\text { Año } & \text { comp. } & \text { parc. } & \% & \text { Fan. } & \% & \text { Importe } & \text { Débito del A. } \\ 1810 & 4 & 10 & 7 & 27 & 3 & 59.620 & 39.900\end{array}$

Entre ambos tipos de venta se había conseguido superar la etapa crítica que supuso la instalación de las tropas francesas en la ciudad.

\title{
Tercera fase
}

Comienza en 1812 cuando las nuevas exigencias napoleónicas, en un momento en que sus tropas atravesaban dificultades bélicas, obligaron al Ayuntamiento a volver a utilizar el sistema de subasta de bienes del común para hacer frente a las nuevas peticiones de metálico. Las subastas se realizaron sin ningún tipo de normativa, simplemente el que más pujaba se llevaba la parcela, aunque ahora se exigía el pago en metálico o en suministros para la tropa, sobre todo vino y cereales ${ }^{31}$. Algunos compradores en anteriores subastas propusieron también al Ayuntamiento las parcelas que deseaban comprar, permitiendo que el precio de venta fuera establecido por los peritos comisionados por las partes. La finalidad de estas propuestas era la de redondear y mejorar las anteriores compras, siendo éste un método claramente fraudulento. Pero nadie protestó y la usurpación continuó su camino beneficiando a aquellos que mejor se habían sabido situar en los momentos cruciales de la contienda.

El cuadro resumen de esta tercera fase de las ventas es éste:

CUADRO 10

Tercera fase de las ventas de bienes del comín

$\begin{array}{cccccccc}\text { Año } & \text { comp. } & \text { parc. } & \% & \text { Fan. } & \% & \text { Importe } & \text { Débito del A. } \\ 1812 & 6 & 7 & 5 & 89 & 9 & 115.715 & \end{array}$

Este tipo de venta, a pesar de su poco peso dentro del conjunto de las ventas de bienes del común, nos ofrece algunas claves sobre la verdadera finalidad de esta expropiación. En primer lugar, la finca media se acerca a las 13 fanegas, mientras que en las primeras fincas subastadas su extensión no superaba las 3 fanegas y media. En segundo lugar, el precio pagado por ellas es sensiblemente inferior al de anteriores subastas, pues mientras en la primera fase el precio por fanega se acercaba a los 1.700 reales y en la segunda subía a los 2.200 , ahora, cuando han sido los propios beneficiarios quienes proponen al Ayuntamiento realizar las ventas, este precio se ha rebajado hasta los 1.300 reales, siendo tierras de la misma calidad y situación y con la ventaja

31. A.H.P. sec. protocolos caja 1.138. En algunos contratos se especifica que fueron los futuros propietarios quienes propusieron al Ayuntamiento la compra de los terrenos. Así se justifica el que en todos los casos, salvo uno, precio de tasa y precio de remate coincidieran. 
de ser parcelas más amplias. Como vemos, un proceso de ventas que se inició para responder a una situación extraordinaria, se va convirtiendo en una formidable oportunidad para aquellos que aún en momentos de conflicto bélico, o precisamente por ello, pueden disponer de liquidez monetaria para reinvertirla en tierra, única fuente segura de beneficios, aunque en algunos casos hubiera que esperar a roturarlas $\mathrm{y}$ ponerlas en funcionamiento para conseguirlos.

\title{
Cuarta fase
}

Donde más claramente se observa el carácter expropiatorio y clasista de la operación de ventas puesta en marcha por el Ayuntamiento, es en la última fase de la misma, conocida como «compensaciones» por las demoliciones realizadas por los franceses para fortificar la ciudad. Los bienes más afectados fueron las huertas y casas de campo que rodeaban Logroño, propiedad todas ellas de los hacendados locales y de los más ricos comerciantes. Esta cuarta y última fase del proceso de enajenación se resume en este cuadro:

\author{
CUADRO 11 \\ Cuarta fase de las ventas de tierras del común
}

$\begin{array}{lccccccc}\text { Año } & \text { comp. } & \text { parc. } & \% & \text { Fan. } & \% & \text { Importe } & \text { Compensac. } \\ 1813 & 20 & 50 & 34 & 557 & 58 & 513.399 & 517.742\end{array}$

Este último «reparto» supuso la mayor cantidad de tierra puesta en circulación durante toda la guerra, así como unas parcelas igualmente extensas, de unas 11 fanegas cada una y a los precios más baratos de todo el período, sólo 930 reales por fanega. Estas cifras definen el último negocio que gracias a la guerra realizaron los inversores locales. La mecánica era sencilla, unas tasaciones de las demoliciones altas y unos precios de las fanegas dadas en compensación bajos para así poder premiar a los afectados con una mayor cantidad de tierra. Los motivos aludidos por los propietarios de las huertas afectadas eran casi siempre el deterioro causado en sus explotaciones por las obras de fortificación realizadas por los franceses:

Leoncio Fernández de Luco, ex regidor perpetuo, reclamó compensaciones por la tala de árboles frutales en su huerta. Las pérdidas se tasaron en 13.020 reales lo que le permitió acceder a la propiedad de 15,8 fanegas de tierra, sin perder por ello la propiedad de la huerta afectada.

Félix Casa, vecino de Alfaro, pidió compensaciones por la destrucción de las tapias de su huerta, éstas se cifraron en 47.860 reales, lo que le supuso 61 fanegas en la Dehesa y 20 árboles en un prado cercano ${ }^{32}$.

Esta usurpación, consentida por un Ayuntamiento cómplice, fue fuertemente contestada una vez terminada la guerra. Las representaciones realizadas por algunos 
regidores de los ayuntamientos posteriores a la guerra intentaron sin éxito que les fueran devueltas al menos las tierras repartidas en concepto de compensaciones:

«El Ayuntamiento que sale, por acta de 31 de mayo del año próximo pasado [1817] [...] me comisionó con los señores regidores Almandoz, Apellaniz y Aguillo pa ra que representasemos [...] al Consejo para que se reintegrasen a los propios de las desmenbraciones hechas para indemnización de demoliciones, con reserva de pedir lo mismo en cuanto a las enajenaciones por venta» 33

Las representaciones continuaron, pero tanto la labor retardataria de algunos elementos del Ayuntamiento, beneficiarios de las ventas, como la labor individual de los mismos ${ }^{34}$, impidieron que las devoluciones se realizaran. Las enajenaciones de bienes del común quedaron definitivamente aprobadas en el año 1827.

Las expropiaciones hasta aquí descritas sólo beneficiaron a una pequeña parte de la población. Conforme avanzaba la guerra los abusos y prepotencia de estos grupos que controlaban el crédito público y que eran los mismos que ya se habían beneficiado del anterior proceso desamortizador -hacendados y comerciantes que dominaban el Ayuntamiento-, fueron en aummento desembocando en la usurpación ilegal de los bienes del común para su propio provecho. Las irregularidades en la concesión de tierras y en la tasación de las demoliciones vinieron a añadirse al clima de profundo trastorno social motivado por la guerra. Mientras, los pequeños campesinos y artesanos se iban hundiendo en una descapitalización acelerada y sus posibilidades de acceso a la propiedad de los medios de producción era cada vez más escasa, lo que motivó que la franja jornalera se ensanchara ${ }^{35}$. El hundimiento del comercio del vino, por úlimo, dejó sin recursos a los pequeños productores que contaban con esos ingresos para redondear la exigua renta familiar. La guerra había acelerado un proceso de cambio social que sólo iba a beneficiar a los grupos sociales más dinámicos y que en Cádiz ya habían dado muestras de tener una alternativa que ofrecer al derrumbe del Antiguo Régimen ${ }^{36}$.

CUADRO 12

Resumen de las enajenaciones de bienes del común

$\begin{array}{ccrrrrrrrc} & \text { Años } & \text { comp. } & \text { parc. } & \% & \text { Fan. } & \% & \text { F/p } & \text { Importe } & \text { Debito A. } \\ 1 & 1809-10 & 40 & 79 & 54 & 281 & 30 & 3,6 & 479.060 & 500.788 \\ 2 & 1810 & 4 & 10 & 7 & 27 & 3 & 2,8 & 59.620 & 39.900 \\ 3 & 1812 & 6 & 7 & 5 & 89 & 9 & 12,10 & 115.715 & - \\ 4 & 1812-13 & 20 & 50 & 34 & 557 & 58 & 11,5 & 513.399 & 517.742 \\ & \text { TOTALES } & 70 & 146 & & 954 & & & 1.167 .794 & 1.057 .430\end{array}$

(Vid. también gráficos 6,7 y 8 ).

33. A.M.Lo. libros de acuerdos, sesión de 1 de enero de 1818 .

34. A.H.P. sec. protocolos caja 1.207 , año 1821 .

35. El número de jornaleros creció entre 1770 y 1818 de 379 a 663. A.M.Lo. para 1770 I.C.E. caja 333 y para 1818 L.A. núm. 7.

36. Artola, M., Los origenes de la España Contemporánea. Madrid 1975. 


\section{Análisis de los compradores}

Las dificultades para llegar a una tipologización satisfactoria del complejo entramado social de fines del siglo XVIII han sido señaladas por numerosos autores ${ }^{37}$.

La vertebración social logroñesa era similar a la de otras partes del Estado, con unas capas que habían sabido aprovechar al máximo las ventajas del comercio del vino, en expansión durante casi todo el siglo XVIII y que en el cambio de siglo tenían una importante masa de capital acumulada sin posibles salidas satisfactorias ${ }^{38}$. Este grupo era heterogéneo en su origen, pues a él pertenecían algunos individuos de la vieja oligarquía local, apartada del poder cuando la explotación vinícola dejó de ser el motor económico de la ciudad, que habían cambiado la vid por el cereal en el momento oportuno. También formaban parte de la nueva élite los más ricos comerciantes que traficaban tanto en lanas -los Martínez y los Crespo- como en capitales - los Santa Cruz- y cuya riqueza había ido siendo invertida en tierras convirtiéndose en 1800 en los mayores propietarios, junto a un importante grupo de hacendados que no estaban vinculados al viñedo como monocultivo y para los que había sido muy ventajosa la subida que los precios del trigo habian experimentado en el último tercio del siglo XVIII. Junto a ellos se encontraban unos pocos maestros artesanos que se estaban transformando lentamente en fabricantes.

Este era el nuevo conglomerado que controlaba el poder local y que dominaba los mercados de capitales y de trabajo. Frente a él se encontraba un numeroso grupo de pequeños labradores-arrendatarios cuya propiedad no superaba las 40 fanegas de tierra de cultivo, una masa aún mayor de jornaleros completamente desposeídos y los ayudantes y aprendices de los maestros artesanos que junto a los criados formaban los estratos desfavorecidos de la ciudad.

Como puede apreciarse la sociedad logroñesa ya no se polarizaba en torno al binomio Nobleza-Estado General, sino que su dinámica económica peculiar había trastocado los viejos sistemas feudales para imponer de una manera muy lenta, pero no por ello menos constante, una nueva ordenación que tenía como distintivo la riqueza de cada cual y su patrimonio, y que dividía a la población de una manera cada vez más acusada en ricos y pobres.

En los apéndices 1 y 2 se detallan los nombres y profesiones de todos los compradores, por ello en este apartado voy a estudiar preferentemente los grupos de compradores afines, y voy a intentar subrayar la importancia de los grupos de «nuevos ricos ${ }^{39}$ en el proceso de compras de las tierras desamortizadas.

\subsection{Compradores en la desamortización de Godoy}

Todos los compradores eran vecinos de Logroño. Algunos no residían en la ciudad permanentemente, como el Señor de Agoncillo pero sí que tenían casa abierta

37. Cfr. las precisiones de AZAgra, J., op. cit., págs. 65-70.

38. Esta situación ha sido señalada por FERNÁNDEZ DE PINEDO, E., en «Coyuntura...», págs. 161-166.

39. Estos «nuevos ricos» pueden identificarse plenamente con la burguesía rural descrita por FERNÁNDEZ DE PINEDo, E., en Crecimiento económico y transformaciones sociales del País Vasco. 1100-1850, Madrid 1974, págs. 350 y ss. y AZAGRA, J., op. cit., págs. 67-70. 
en ella. Su número fue solamente de 33 , lo que significa que cada uno compró por término medio una superficie de 37 fanegas de tierra. En el cuadro siguiente se muestra la distribución de estas compras por el tipo de tierra adquirido:

CUADRO 13

Tipo de tierra comprada por cada grupo

\begin{tabular}{lrrrrrrrrc} 
& Com. & Regadí & \multicolumn{1}{c}{$\%$} & Secano & $\%$ & viña & $\%$ & Total & $\%$ \\
Comerciantes & 10 & 326,9 & 30,5 & 84,6 & 53 & & & 411,3 & 33 \\
Artesanos & 1 & 2,6 & 0,2 & & & & & 2,6 & 0,2 \\
Hacendados & 10 & 237,5 & 22,2 & 73,6 & 47 & 7 & 100 & 317,11 & 26,4 \\
Labradores & 5 & 25,6 & 2,4 & & & & & 25,6 & 2 \\
Clero & 1 & 4 & 0,4 & & & & & 4 & 0,3 \\
Fabricantes & 2 & 9,6 & 0,9 & & & & & 9,6 & 0,8 \\
Nobles & 2 & 444 & 41,6 & & & & & 444 & 36 \\
Prof. Lib. & 2 & 18,4 & 1,8 & & & & & 18,4 & 1,3 \\
TOTALES & 33 & 1.068 & & 158 & & 7 & & 1.233 &
\end{tabular}

En este cuadro puede apreciarse, en una primera aproximación general, cómo fueron los grupos caracterizados como «nuevos ricos» los que más se aprovecharon de esta desamortización. Entre los comerciantes y los hacendados coparon el $59 \%$ de las tierras puestas en subasta. El tercer grupo, primero en importancia por la magnitud de las tierras compradas, tiene unas características especiales que necesitan una explicación detallada. Es el grupo denominado como Nobles y que sólo agrupa a dos personas. Uno de ellos era el Señor de Agoncillo que adquirió 20 fanegas de regadío. El otro es el Marqués de San Nicolás que antes de esta desamortización no tenía posesiones en Logroño. Procedente de Briones, donde tenía su casa solariega y todas sus tierras, las adversas condiciones económicas que imperaban en esa localidad de monocultivo de la vid ${ }^{40}$ le empujaron a reinvertir las ganancias en otras zonas donde la bondad de la tierra de regadío acolchonaba las fuertes crisis de subsistencias padecidas en su lugar de origen. La desamortización le permitió acceder a esas tierras que tanto anhelaba a juzgar por el dinero que invirtió en su compra. Avecindado definitivamente en Logroño después de la Guerra de la Independencia fue el primer Alcalde Constitucional que tuvo la ciudad en el Trienio Liberal ${ }^{41}$. Este es un claro ejemplo de la introducción de parte de la nobleza local en los grupos sociales más dinámicos empujada en su transformación social por la coyuntura vinícola comarcal, que coadyuvó, con sus formas de explotación precapitalista sumamente integrada en el mercado, a que esta nobleza dejara de explotar sus tierras de una forma absentista y se preocupara más de la producción de las mismas y de su racionalización. 
Si estudiamos ahora la distribución de las compras de acuerdo a la superficie que cada uno compró, vemos aún más clara la incidencia de estos grupos en el resultado final de las ventas:

\section{CUADRO 14}

Superficies adquiridas por cada grupo distribuidas por segmentos de extensión (en fanegas)

\begin{tabular}{lccrrrc} 
& 0 a 10 & 11 a 30 & 31 a 100 & +100 & \multicolumn{1}{c}{ Pagos } & $\%$ \\
Comerciantes & $4-20,4$ & $3-58,10$ & $2-174,3$ & $1-157,10$ & 636.482 & 28,5 \\
Artesanos & $1-2,6$ & & & & 2.200 & - \\
Hacendados & $4-27,10$ & $2-31,3$ & $4-258,10$ & & 487.188 & 21,9 \\
Labradores & $4-25,6$ & & & & 21.325 & 0,9 \\
Clero & $1-4$ & & & & 7.100 & 0,3 \\
Fabricantes & $2-9,6$ & & & & 8.254 & 0,5 \\
Nobles & & $1-20$ & & $1-424$ & 1.035 .000 & 46,5 \\
Prof. Lib. & $1-2,4$ & $1-16$ & & & 29.000 & 1,4 \\
TOTALES & $18-92$ & $7-126,1$ & $6-433,1$ & $2-581,10$ & 2.226 .549 & 42 \\
\% & $54-7$ & $22-10$ & $18-35$ & $6-48$ & &
\end{tabular}

En este cuadro puede apreciarse cómo fueron muy pocas personas, solamente 8 , las que adquirieron grandes superficies de tierra, más de 31 fanegas, siendo estas personas, tres comerciantes, cuatro hacendados y un noble quienes pudieron aprovechar al máximo las facilidades concedidas por el Gobierno, constituyéndose como los principales beneficiarios de un proceso desamortizador hecho a su medida.

Por grupos los que más pagaron por fanega de tierra comprada fueron los Nobles, que desembolsaron 2.331 reales, les siguen los comerciantes con 1.720 y los hacendados que pagaron algo menos, 1.538 reales por fanega. La participación del resto de los grupos es insignificante, pues sólo los profesionales superan la barrera del $1 \%$ del total pagado, siendo sus parcelas un poco más caras que las de los hacendados, 1.582 reales.

42. En este cuadro se incluyen las 59 fanegas que no tienen precio. Para saber el precio que cada grupo pagó por fanega de tierra hay que restarlas de la siguiente forma:

$\begin{array}{lcc}\text { Comerciantes } & 41,5 & \text { fanegas } \\ \text { Hacendados } & 1,2 & \text { " } \\ \text { Fabricantes } & 6,6 & \text { " } \\ \text { Labradores } & 9,11 & \text { " } \\ \text { Total } & 59 & \text { Fanegas }\end{array}$




\subsection{Compradores de bienes del común}

La venta de bienes del común permitió, por su especial naturaleza, a un grupo mayor acceder a la propiedad, pero conservó rasgos similares a los que hemos observado para la desamortización de Godoy. Los grupos más beneficiados por este nuevo «reparto» de tierras volvieron a ser aquellos que controlaban todas las instancias del gobierno municipal, promotor, esta vez, de la privatización de suelo comunal.

La enajenación completa de los escasos bienes comunales que le quedaban al Ayuntamiento de Logroño supuso en la práctica el final de las relaciones que durante todo el Antiguo Régimen el poder había establecido con sus vasallos. A partir de ahora los grupos más desfavorecidos no iban a poder acudir a por la leña, la caza y otras necesidades básicas que cubrían gracias a la existencia de estas grandes dehesas comunes. Tampoco les quedaba la posibilidad de roturaciones marginales, pues el control ejercido desde el poder impidió que se abrieran nuevas tierras. El acceso directo de los poderosos a ellas estaba en la base de estas prohibiciones. Veamos en el siguiente cuadro cómo se las repartieron:

CUADRO 15

Superficie adquirida por cada grupo y número de compradores

$\begin{array}{lccccc} & \text { compradores } & \begin{array}{c}\text { fanegas } \\ \text { compradas }\end{array} & \% & \text { Pagos } & \% \\ \text { Comerciantes } & 20 & 355,2 & 37 & 480.689 & 41 \\ \text { Artesanos } & 1 & 3,4 & 0,4 & 7.450 & 0,6 \\ \text { Hacendados } & 18 & 358 & 37,5 & 379.275 & 32,5 \\ \text { Labradores } & 13 & 76,4 & 8 & 94.700 & 8,1 \\ \text { Clero } & 2 & 34,6 & 3,6 & 48.800 & 4,2 \\ \text { Fabricantes } & 2 & 63,4 & 6,6 & 70.680 & 6 \\ \text { Títulos } & 2 & 13 & 1,4 & 27.800 & 2,4 \\ \text { Prof. Lib. } & 3 & 50,4 & 5,3 & 58.400 & 5,2 \\ \text { TOTAL } & 61 & 954 & & 1.167 .794 & \end{array}$

Los rasgos de este cuadro son similares al de la desamortización, si exceptuamos alguna pequeña matización, como es la del mayor peso de los labradores, lógica si consideramos la forma y los motivos de las enajenaciones y que la fanega de tierra en esta ocasión fue más barata que durante las ventas anteriores -1.200 reales frente a los 2.144 de la desamortización de Godoy.

La poca participación de Nobles puede explicarse por el hecho de que no estuvieron en Logroño durante la Guerra, ya que teniendo la posibilidad de huir hacia zonas más seguras, no la desaprovecharon.

La distribución de los compradores según la superficie adquirida también muestra esta mayor participación de los logroñeses en las ventas, aunque nuevamente son los grandes propietarios quienes más se beneficiaron, pues sus compras supusieron el $63,5 \%$ de la tierra vendida: 


\section{CUADRO 16 \\ Distribución de las compras por segmentos de extensión}

(en fanegas)

$\begin{array}{lcccc} & 0 \text { a } 10 & 11 \text { a } 30 & 31 \text { a } 49 & 50 \text { a } 100 \\ \text { Comerciantes } & 11-46,4 & 4-85,4 & 3-110,1 & 2-113,6 \\ \text { Artesanos } & 1-3,4 & & & \\ \text { Hacendados } & 11-54,11 & 3-48,9 & & \\ \text { Labradores } & 12-57 & 1-19,4 & & \\ \text { Clero } & 1-2 & & 1-32,6 & 1-59 \\ \text { Fabricantes } & 1-4,4 & & & \\ \text { Títulos } & 2-13 & & 1-34 & \\ \text { Prof. Lib. } & 2-16,4 & 8-153,5 & 5-176,6 & 7-426,10 \\ \text { TOTAL } & 41-197,3 & 13-16 & 8-18,5 & 12-45 \\ \text { \% } & 67-20,5 & & & \end{array}$

\section{Conclusiones}

Las desamortizaciones estudiadas fueron el último paso para que los «nuevos ricos» redondearan de una forma definitiva su privilegiada posición en la ciudad. Las alternativas que buscaron para evitar que el retroceso coyuntural vinícola les afectara se encaminaron a la acumulación de la mayor cantidad de tierras posible en sus manos, ya que la inestabilidad internacional no permitía aventurarse en negocios mercantiles de dudoso rendimiento. Las dificultades del mercado interior de tierras hacían poco rentable su compra 43 y las sucesivas emisiones de deuda cada vez encontraban menos eco entre los posibles inversores por el descrédito de la entidad emisora. La liberalización de parte de la tierra de labor fue la respuesta que el gobierno ilustrado dio para terminar con la inactividad de estos capitales sin salidas ventajosas y que ante esta oportunidad de rentabilidad inmediata no dudaron en aprovecharla al máximo, sucediendo en Logroño lo mismo que en otras zonas estudiadas en lo que se refiere a superficies desamortizadas y principales grupos beneficiados por las compras.

La superficie total desamortizada entre 1801 y 1813 supuso un $10 \%$ de la tierra que estaba en cultivo lo que produjo una nueva distribución de la propiedad, cuya característica principal a partir de estos momentos fue una mayor concentración, ya

43. El estudio detenido de la curva del precio de la tierra entre 1750 y 1833 muestra como la presión compradora incrementa fuertemente los precios cuando el comercio del vino inicia su retroceso, debido a la escasez de tierra que se ofertaba. 
observada desde los últimos años del siglo XVIII y que se refleja en la comparación entre el catastro del 1770 y el de $1818^{44}$.

Pero la conclusión más importante a la que hay que llegar después del estudio de este período es a la de que ya en estos años se está formando un conglomerado de grupos con intereses afines y de similares características: acumulación de capitales provenientes ya del comercio, ya de la especulación con granos panificables o simplemente de la elevación de las rentas de las grandes explotaciones y que en una coyuntura negativa -guerras, crisis de $1804 \ldots$ - deben buscar nuevas fórmulas para que esos capitales puedan reproducirse, chocando frontalmente con unas normativas que impedían que la más atractiva de las inversiones, la tierra, fuera productiva. Su principal preocupación a partir de ese momento fue la de ir minando la estructura del Antiguo Régimen en España, definiendo así el modelo de transición que finalmente se produciría en nuestro país, un reparto de la tierra entre los grupos burgueses emergentes y una nobleza en cambio y dispuesta a adaptarse a un sistema que le iba a permitir conservar sus propiedades y aumentar sus beneficios gracias a la disolución de las antiguas trabas feudales.

44. Entrar en las comparaciones entre el catastro de 1770 y el apeo de 1818 no es el objetivo de este artículo. Sirva como ejemplo que en 1770 el $13 \%$ de los propietarios -grandes propietarios- controlaba 7.000 fanegas -el $31 \%$ de la superficie cultivada- mientras que en 1818 el porcentaje se había reducido al $10 \%$ pero controlaban ya 8.700 fanegas que suponía el $36 \%$ de la tierra cultivada. 
APENDICE 1

\section{DESAMORTIZACION DE GODOY EN LOGROÑO}

\begin{tabular}{|c|c|c|c|c|c|c|}
\hline VENDEDOR & PARC. & SUP. & TIP. & COMPRADOR/PROF. & TASA & REMATE \\
\hline OP ESPINOSA/ & 1 & 6 & $\mathrm{R}$ & MIGUEL MACERAS & 15.600 & \\
\hline SANTIAGO & 1 & 5 & $\mathrm{R}$ & HACENDADO & 11.050 & \\
\hline TOTAL & 2 & 11 & $\mathrm{R}$ & & 26.650 & 30.500 \\
\hline OP ISABEL DE & 10 & 28,8 & $\mathrm{R}$ & MARCIAL MARTINEZ & 32.300 & 40.700 \\
\hline VEDIA / REDONDA & & & & COMERCIANTE & & \\
\hline CAP. BAZAN/ & 1 & 5 & $\mathrm{R}$ & & 8.800 & 13.500 \\
\hline SAN BLAS & 1 & 4 & $\mathrm{~S}$ & & & 1.100 \\
\hline ANIVERSARIOS & 13 & 32,7 & $\mathrm{R}$ & & & S.P. \\
\hline REDONDA & 1 & 19 & $\mathbf{R}$ & & & 55.000 \\
\hline \multirow[t]{3}{*}{ TOTAL } & 25 & 86,3 & $\mathrm{R}$ & & & 109.200 \\
\hline & 1 & 4 & S & & & 1.100 \\
\hline & 26 & 90,3 & & & & 110.300 \\
\hline $\begin{array}{l}\text { OP M. HERAS/ } \\
\text { PALACIO }\end{array}$ & 27 & 84 & $\mathrm{R}$ & $\begin{array}{c}\text { PEDRO L. MORENTIN } \\
\text { COMERCIANTE }\end{array}$ & 145.900 & 202.170 \\
\hline OP PADURA/ & 7 & 47,3 & $\mathrm{~S}$ & FCO. JAVIER CRESPO & 17.630 & \\
\hline \multirow[t]{2}{*}{ PALACIO } & 14 & 33,8 & $\mathrm{R}$ & HACENDADO & 75.200 & \\
\hline & 2 & 7 & $\mathrm{~V}$ & & 8.023 & \\
\hline TOTAL & 23 & 87,11 & & & 100.853 & 115.000 \\
\hline OP AYALA/ & 2 & 6 & $\mathrm{R}$ & LEONCIO FERNANDEZ & 5.500 & 5.500 \\
\hline PALACIO & & & & HACENDADO & & \\
\hline ANIVERSARIOS/ & 1 & 3 & $\mathrm{R}$ & & & 13.954 \\
\hline REDONDA & 1 & 1,2 & $\mathrm{R}$ & & & S.P. \\
\hline TOTAL & 4 & 10,2 & & & & 19.454 \\
\hline
\end{tabular}


LA CRISIS DEL MUNICIPIO LOGROÑES

\begin{tabular}{|c|c|c|c|c|c|c|}
\hline VENDEDOR & PARC. & SUP. & TIP. & COMPRADOR/PROF. & TASA & REMATE \\
\hline ORDEN SAN & 1 & 3 & $\mathrm{R}$ & H. DE LA CUESTA & 6.500 & 9.300 \\
\hline FRANCISCO & & & & COMERCIANTE & & \\
\hline OP J. SANTANDER & 6 & 16 & $\mathrm{R}$ & VICENTE CHASCO & 21.400 & 26.700 \\
\hline PALACIO & & & & ABOGADO & & \\
\hline ANIVERSARIOS & 3 & 8,8 & $\mathrm{R}$ & JOSEFA ALBENIZ & - & 13.400 \\
\hline REDONDA & & & & VDA. HACENDADA & & \\
\hline CAP. BAZAN & 1 & 8 & $\mathrm{R}$ & JOSE SOTO & 26.400 & 32.500 \\
\hline SAN BLAS & & & & COMERCIANTE & & \\
\hline CAP. SAN MIGUEL & 9 & 69,6 & $\mathrm{~S}$ & DOMINGO STA. CRUZ & 19.115 & 26.500 \\
\hline CAP. BAZAN & 1 & 5 & $\mathrm{R}$ & COMERCIANTE & 6.600 & 11.500 \\
\hline \multicolumn{7}{|l|}{ SAN BLAS } \\
\hline OP ALBIA & 3 & 5 & $\mathbf{R}$ & & 9.600 & 13.200 \\
\hline \multicolumn{7}{|l|}{ AYUNTAMIENTO } \\
\hline ANIVERSARIOS & 11 & 44,4 & $\mathrm{R}$ & & - & 84.018 \\
\hline ABADIA S. GIL & 10 & 34 & $\mathbf{R}$ & & - & 57.950 \\
\hline \multicolumn{7}{|l|}{ REDONDA } \\
\hline \multirow[t]{3}{*}{ TOTAL } & 25 & 88,4 & $\mathrm{R}$ & & & 166.668 \\
\hline & 9 & 69,6 & $\mathrm{~S}$ & & & 26.500 \\
\hline & 34 & 157,10 & & & & 193.168 \\
\hline
\end{tabular}

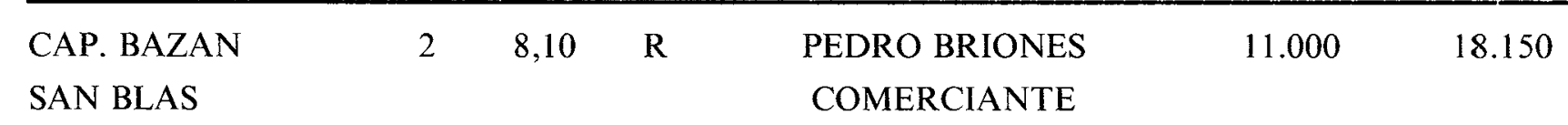

\begin{tabular}{|c|c|c|c|c|c|c|}
\hline ANIVERSARIOS & 3 & 9 & $\mathrm{R}$ & & & 15.400 \\
\hline REDONDA & 4 & 7,6 & $\mathrm{R}$ & & & S.P. \\
\hline TOTAL & 9 & 25,4 & & & & 33.550 \\
\hline CTO. MERCED & 1 & 3,6 & $\mathrm{R}$ & $\begin{array}{l}\text { JULIAN DIEZ } \\
\text { LABRADOR }\end{array}$ & 3.300 & 2.200 \\
\hline $\begin{array}{l}\text { DIPUTACION } \\
\text { PALACIO } \\
\end{array}$ & 1 & 5 & $\mathrm{R}$ & $\begin{array}{c}\text { ALEJANDRO BERJES } \\
\text { LABRADOR }\end{array}$ & 6.600 & 7.400 \\
\hline $\begin{array}{l}\text { OP PALACIOS } \\
\text { PALACIO }\end{array}$ & 1 & 20 & $\mathrm{R}$ & $\begin{array}{l}\text { JOAQUIN DE FRIAS } \\
\text { SR. DE AGONCILLO }\end{array}$ & 44.000 & 60.000 \\
\hline $\begin{array}{l}\text { ANIVERSARIOS } \\
\text { REDONDA } \\
\end{array}$ & 1 & 2,6 & $\mathbf{R}$ & $\begin{array}{c}\text { BERNABE IBAÑNEZ } \\
\text { ARTESANO }\end{array}$ & & 2.200 \\
\hline $\begin{array}{l}\text { ANIVERSARIOS } \\
\text { REDONDA }\end{array}$ & 6 & 32 & $\mathrm{R}$ & $\begin{array}{l}\text { JOSE CRESPO } \\
\text { HACENDADO }\end{array}$ & & 73.412 \\
\hline
\end{tabular}


JESUS J. ALONSO CASTROVIEJO

\begin{tabular}{|c|c|c|c|c|c|c|}
\hline VENDEDOR & PARC. & SUP. & TIP. & COMPRADOR/PROF. & TASA & REMATE \\
\hline ANIVERSARIOS & 10 & 22,6 & $\mathrm{R}$ & JUAN A. GARCIA ARTECHE & & 40.394 \\
\hline REDONDA & & & & COMERCIANTE & & \\
\hline ANIVERSARIOS & 4 & 8 & $\mathrm{R}$ & FERNANDO AMUSCO & & 12.800 \\
\hline REDONDA & & & & COMERCIANTE & & \\
\hline ANIVERSARIOS & 1 & 20 & $\mathrm{R}$ & JOSE DAVALOS & & 41.800 \\
\hline REDONDA & & & & HACENDADO & & \\
\hline ANIVERSARIOS & 2 & 3,6 & $\mathrm{R}$ & JULIAN BLAZQUEZ & & 2.000 \\
\hline REDONDA & & & & HACENDADO & & \\
\hline ANIVERSARIOS & 1 & 2,4 & $\mathrm{R}$ & BERNABE AGUILLO & & 2.300 \\
\hline REDONDA & & & & ADMINISTRADOR & & \\
\hline ANIVERSARIOS & 1 & 3 & $\mathrm{R}$ & JUSTO ARANCETA & & 8.254 \\
\hline$\underline{\text { REDONDA }}$ & & & & FABRIC. DE CURTIDOS & & \\
\hline ANIVERSARIOS & 2 & 11 & $S$ & ANTONIO ARAMAYONA & & 2.300 \\
\hline REDONDA & & & & COMERCIANTE & & \\
\hline ANIVERSARIOS & 1 & 4 & $\mathrm{R}$ & CONVENTO DE LA & & 7.100 \\
\hline REDONDA & & & & MERCED & & \\
\hline ANIVERSARIOS & 1 & 7,1 & $\mathrm{R}$ & PRUDENCIO SOTO & & 11.725 \\
\hline REDONDA & & & & LABRADOR & & \\
\hline ANIVERSARIOS & 2 & 8,5 & $\mathrm{R}$ & PABLO REGADERA & & S.P. \\
\hline REDONDA & & & & LABRADOR & & \\
\hline ANIVERSARIOS & 2 & 6,6 & $\mathrm{R}$ & SILVESTRE ECHEVARRIA & & S.P. \\
\hline REDONDA & & & & FABRIC. DE CURTIDOS & & \\
\hline ANIVERSARIOS & 1 & 1,6 & $\mathrm{R}$ & SILVESTRE SAENZ & & S.P. \\
\hline REDONDA & & & & LABRADOR & & \\
\hline ANIVERSARIOS & 1 & 1,4 & $\mathrm{R}$ & LEON ECHEVARRIA & & S.P. \\
\hline REDONDA & & & & COMERCIANTE & & \\
\hline OP SALAZAR & 16 & 58,8 & $\mathrm{R}$ & LINA HUERTA & & 76.401 \\
\hline REDONDA & & & & VDA. HACENDADA & & \\
\hline OP LOYOLA & 2 & 12 & $\mathrm{~S}$ & ISIDRO AYALA & 6.100 & \\
\hline AYUNTAMIENTO & 6 & 19,6 & $\mathrm{R}$ & HACENDADO & 35.240 & 52.000 \\
\hline ANIVERSARIOS & 1 & 14 & $\mathrm{~S}$ & & & 1.400 \\
\hline REDONDA & 16 & 34,9 & $\mathrm{R}$ & & & 53.817 \\
\hline \multirow[t]{3}{*}{ TOTAL } & 3 & 26 & $\mathrm{~S}$ & & & \\
\hline & 22 & 54,3 & $\mathrm{R}$ & & & \\
\hline & 25 & 80,3 & & & & 107.217 \\
\hline
\end{tabular}


LA CRISIS DEL MUNICIPIO LOGROÑES

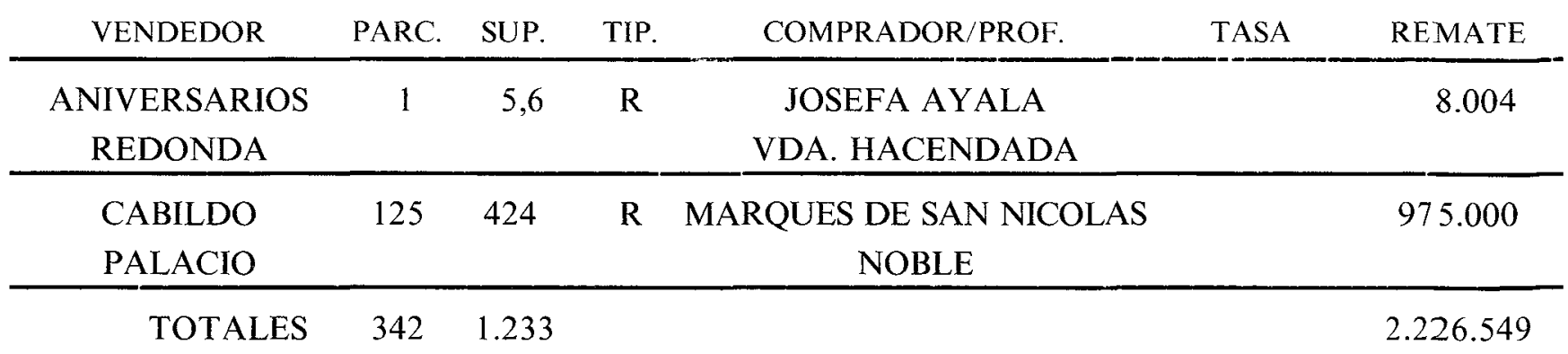

APENDICE 2

VENTA DE BIENES DEL COMUN

COMPRADORES

PROFESION

Fase Parc. Sup. Tasa Remate Débito Ay.

PEDRO PEREZ

COMERCIANTE

\begin{tabular}{llllll}
1 & 1 & 12 & & 20.020 & 15.933 \\
3 & 2 & 16,9 & 15.050 & 15.050 & \\
\cline { 2 - 3 } & 3 & 28,9 & & 35.070 & \\
\hline
\end{tabular}

\begin{tabular}{|c|c|c|c|c|c|c|}
\hline \multicolumn{7}{|c|}{ SILVANO ARAMAYONA } \\
\hline COMERCIANTE & 1 & 1 & 2 & & 9.000 & 3.260 \\
\hline \multicolumn{7}{|c|}{ NICOLAS Y JACINTO DE LA MATA } \\
\hline RELIGIOSOS & 1 & 1 & 2 & & 6.800 & 7.220 \\
\hline \multicolumn{7}{|c|}{ MARIANO BALMASEDA } \\
\hline COMERCIANTE & 1 & 1 & 2 & & 6.800 & 6.837 \\
\hline \multicolumn{7}{|c|}{ MARIANO ARAMAYONA } \\
\hline \multirow[t]{3}{*}{ COMERCIANTE } & 1 & 3 & 5,7 & & 13.500 & 12.180 \\
\hline & 4 & 3 & 19 & & 15.240 & 13.270 \\
\hline & & 6 & 24,7 & & 28.740 & 28.450 \\
\hline \multicolumn{7}{|c|}{ FELIPE SALVATIERRA } \\
\hline COMERCIANTE & 1 & 1 & 2 & & 6.200 & 4.217 \\
\hline \multicolumn{7}{|c|}{ FRANCISCO JOSE CRESPO } \\
\hline HACENDADO & 1 & 1 & 2 & & 6.500 & 7.640 \\
\hline \multicolumn{7}{|c|}{ DOMINGO SANTA CRUZ } \\
\hline \multirow[t]{4}{*}{ COMERCIANTE } & 1 & 6 & 13 & & 30.500 & 45.348 \\
\hline & 1 & 1 & 5,6 & 8.250 & 15.000 & 15.000 \\
\hline & 3 & 1 & 18 & 18.000 & 18.000 & \\
\hline & & 8 & 36,6 & & 63.500 & 60.348 \\
\hline
\end{tabular}


JESUS J. ALONSO CASTROVIEJO

COMPRADORES

PROFESION

Fase Parc. Sup.

Tasa

Remate

Débito Ay.

MANUEL ORBE

COMERCIANTE

1

$3 \quad 8$

8.000

16.900

15.792

MARQUESA DE SOMERUELOS

NOBLE

$1 \quad 1$

$4 \quad 4.000$

6.400

5.750

CASTOR DE LA CALLE

\begin{tabular}{|c|c|c|c|c|c|c|}
\hline HACENDADO & 1 & 2 & 8 & 8.000 & 9.200 & 10.312 \\
\hline \multicolumn{7}{|l|}{ DIEGO LOPEZ } \\
\hline LABRADOR & 1 & 2 & 8 & 8.000 & 12.350 & 9.102 \\
\hline \multicolumn{7}{|c|}{ EUSEBIO SANTOS } \\
\hline LABRADOR & 2 & 3 & 7 & 14.700 & 20.812 & 20.830 \\
\hline \multicolumn{7}{|c|}{ MANUEL DE FEE } \\
\hline FABRICANTE & 2 & 2 & 4,4 & 7.000 & 12.080 & 5.274 \\
\hline \multicolumn{7}{|c|}{ FLORENCIO GARCIA } \\
\hline \multirow[t]{3}{*}{ FABRICANTE } & 1 & 1 & 4,6 & 4.500 & 10.000 & 12.929 \\
\hline & 4 & 1 & 54,6 & & 48.600 & 48.600 \\
\hline & & 2 & 59 & & 58.600 & 61.529 \\
\hline
\end{tabular}

LUIS VIGUERA

LABRADOR

$1 \quad 3$

39

9.700

$9.700 \quad 10.204$

MIGUEL CASTELLANOS

LABRADOR

1

4.000

4.040

5.140

ALEJANDRO TORRALBA

HACENDADO

2

4

10,8

19.333

19.333

10.041

ANTONIO ALONSO

LABRADOR

1

1

4

3.600

5.600

6.418

MANUEL MURGA

LABRADOR

1

13

3.000

5.100

6.664

JUAN A. GARCIA ARTECHE

COMERCIANTE

$1 \quad 1 \quad 2$

6.100

6.384

JOSE APELLANIZ

LABRADOR

3

$1 \quad 6,6$

9.100

9.100

MARCIAL MARTINEZ

COMERCIANTE

\begin{tabular}{rrrrrr}
1 & 5 & 5 & 5.100 & 8.400 & 8.732 \\
4 & 7 & 53 & & 59.550 & 59.458 \\
\cline { 2 - 3 } & & & 67.950 & 68.190 \\
\hline
\end{tabular}


LA CRISIS DEL MUNICIPIO LOGROÑES

COMPRADORES

PROFESION

Fase Parc. Sup

Tasa

Remate

Débito Ay.

MATIAS MARTINEZ

LABRADOR

1

$3 \quad 5,6$

4.800

4.800

4.048

JULIAN BLAZQUEZ

HACENDADO

MARQUES DE SAN NICOLAS

TITULO

$1 \quad 4 \quad 9$

9.900

21.400

22.920

PEDRO BRIONES

COMERCIANTE

$\begin{array}{lll}2 & 1 & 5\end{array}$

7.395

7.395

3.755

VICENTE RUIZ DE LA CAMARA

HACENDADO

$1 \quad 1 \quad 2$

8.400

8.128

GUADALUPE CAMARA

VIUDA HACENDADA

$\begin{array}{lll}1 & 1 & 2\end{array}$

7.300

9.350

PABLO REGADERA

LABRADOR 1

12

6.700

6.498

SANTIAGO ALMANDOZ

COMERCIANTE

1

$1 \quad 3$

3.300

4.600

4.736

JACINTA REMON

COMERCIANTE

\begin{tabular}{ccc}
1 & 7 & 15,10 \\
1 & 1 & 24 \\
4 & 1 & 2,6 \\
\hline & -9 & 42,4
\end{tabular}

23.300

47.750

61.772

23.300

23.334

1.87

1.800

FRANCISCO MATEO
COMERCIANTE

$\begin{array}{lll}1 & 1 & 2\end{array}$

7.500

4.162

ANSELMO IBARRA

HACENDADO

$\begin{array}{lll}1 & 1 & 13,9\end{array}$

10.000

13.553

FRANCISCO RUIZ

ARTESANO

13

3,6

3.850

7.450

10.921

ANTONIA DEL RIO

VIUDA HACENDADA

12

7,3

7.150

10.400

9.189

CESAREO ANTONIO BENITO DEL VALLE

HACENDADO

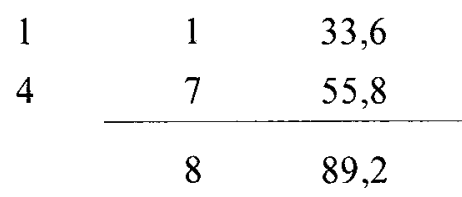

30.550

30.550

28.194

41.100

46.160

71.650

74.354 
JESUS J. ALONSO CASTROVIEJO

COMPRADORES

PROFESION

Fase Parc. Sup.

Tasa Remate

Débito Ay.

GREGORIO MATEO

LABRADOR

$1 \quad 1 \quad 3,6$

3.500

3.651

RITA BRETON

VDA. HACENDADA

1

$3 \quad 3$

$3 \quad 3.200$

4.500

6.494

JULIAN MURO

COMERCIANTE

$\begin{array}{lll}1 & 3 & 19,6\end{array}$

17.950

26.500

26.429

FELIX LOPEZ (SORIA)

COMERCIANTE

$1 \quad 4$

12,6

23.400

23.400

23.400

SATURNINO MOZUN

HACENDADO

\begin{tabular}{lrr}
1 & 1 & 4 \\
4 & 1 & 7 \\
\hline & 2 & 11
\end{tabular}

3.600

$4.600 \quad 6.207$

$\begin{array}{r}9.896 \quad 9.900 \\ \hline\end{array}$

$14.496 \quad 16.107$

GABRIEL GARCIA LUSA

\begin{tabular}{lcccccc} 
COMERCIANTE & 1 & 1 & 3,6 & 5.250 & 8.500 & 4.000 \\
\hline $\begin{array}{l}\text { JUSTO ZURBANO } \\
\text { LABRADOR }\end{array}$ & 1 & 1 & 3,6 & 3.500 & 4.400 & 4.240 \\
\hline $\begin{array}{l}\text { MANUEL CAREAGA } \\
\text { ABOGADO }\end{array}$ & 3 & 1 & 10 & 550 & 550 \\
\hline
\end{tabular}

JUAN VIDEGARAY

\begin{tabular}{lllllll} 
COMERCIANTE & 3 & 1 & 31,3 & 31.000 & 31.000 & \\
\hline SEMINARIO & 4 & 1 & 32,6 & 42.000 & 42.046 \\
\hline
\end{tabular}

LEONCIO FERNANDEZ DE LUCO

HACENDADO

4

$6 \quad 54,2$

52.202

53.268

AQUILINO UBAGO

ADMINISTRADOR

4

$1 \quad 6,6$

6.850

6.850

VICENTE LAZCANO

COMERCIANTE

$4 \quad 2$

12.809

12.809

VICENTE SAENZ DE CALAHORRA

COMERCIANTE

4

$1 \quad 7$

8.400

8.361

JACINTA OYARZUN

VDA. HACENDADA

4

$2 \quad 50$

39.200

39.420

ANTONIO ULLOA

HACENDADO

4

4

23,6

21.504

21.436 
LA CRISIS DEL MUNICIPIO LOGROÑES

COMPRADORES

PROFESION

Fase Parc. Sup.

Tasa

Remate

Débito Ay.

FLORIANO ALVARO

HACENDADO

4

$\begin{array}{lll}3 & 8 & 1.950\end{array}$

1.923

JOSE PEREZ DEL NOTARIO

COMERCIANTE

4

55,6

37.400

37.541

FELIX CASA (ALFARO)

HACENDADO

4

61

47.850

47.860

MIGUEL RAON (CALAHORRA)

HACENDADO

4

7,6

7.575

7.442

ANTONIO GILBERTE

ESCRIBANO

4

34

51.000

51.000

FCO. JAVIER CRESPO

HACENDADO 3

6,6

26.000

42.015

BALTASAR RUIZ

LABRADOR

4

2

19,4

7.600

7.600

BERNARDINO ALONSO

LABRADOR

4

4

11

998

998

TOTAL

146

954

\begin{tabular}{ll}
$1.167 .794 \quad 1.035 .096$ \\
\hline
\end{tabular}




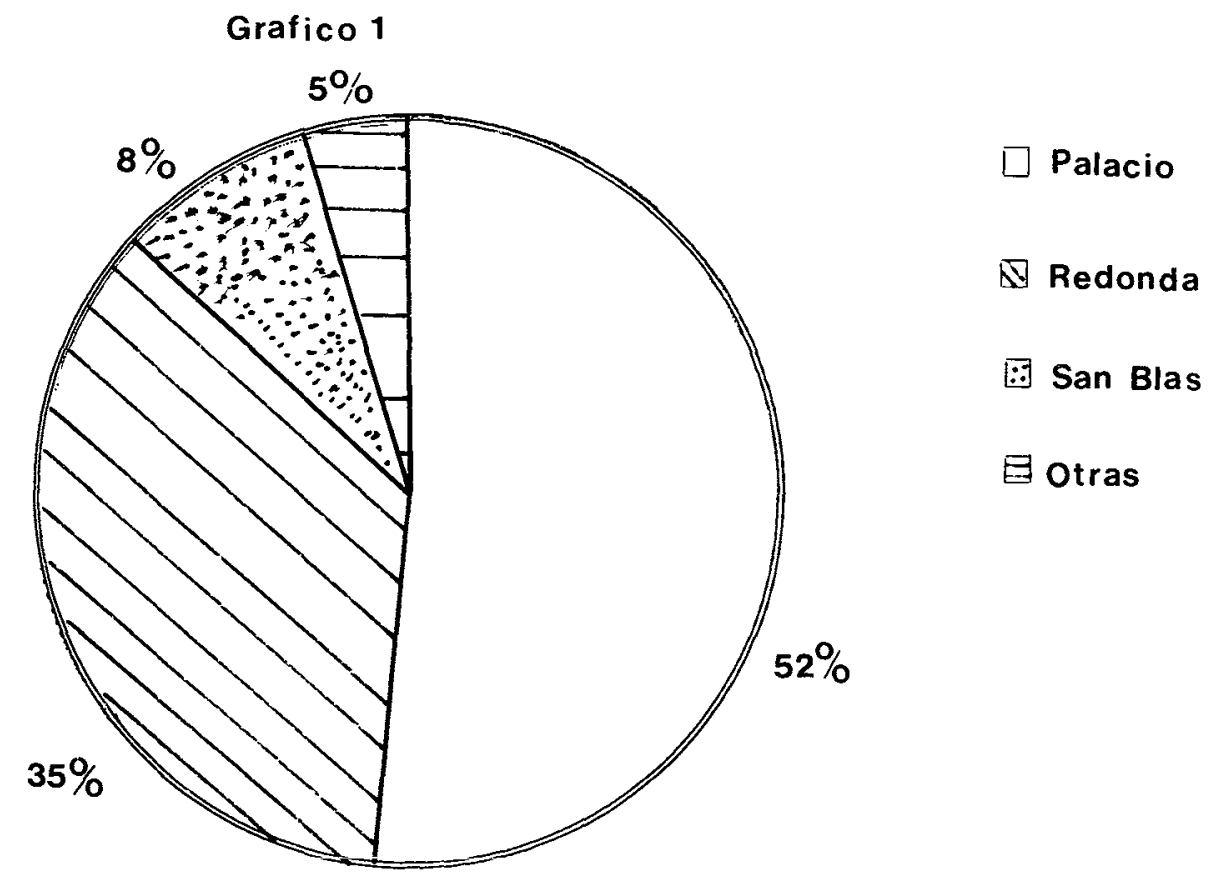

Instituciones afectadas

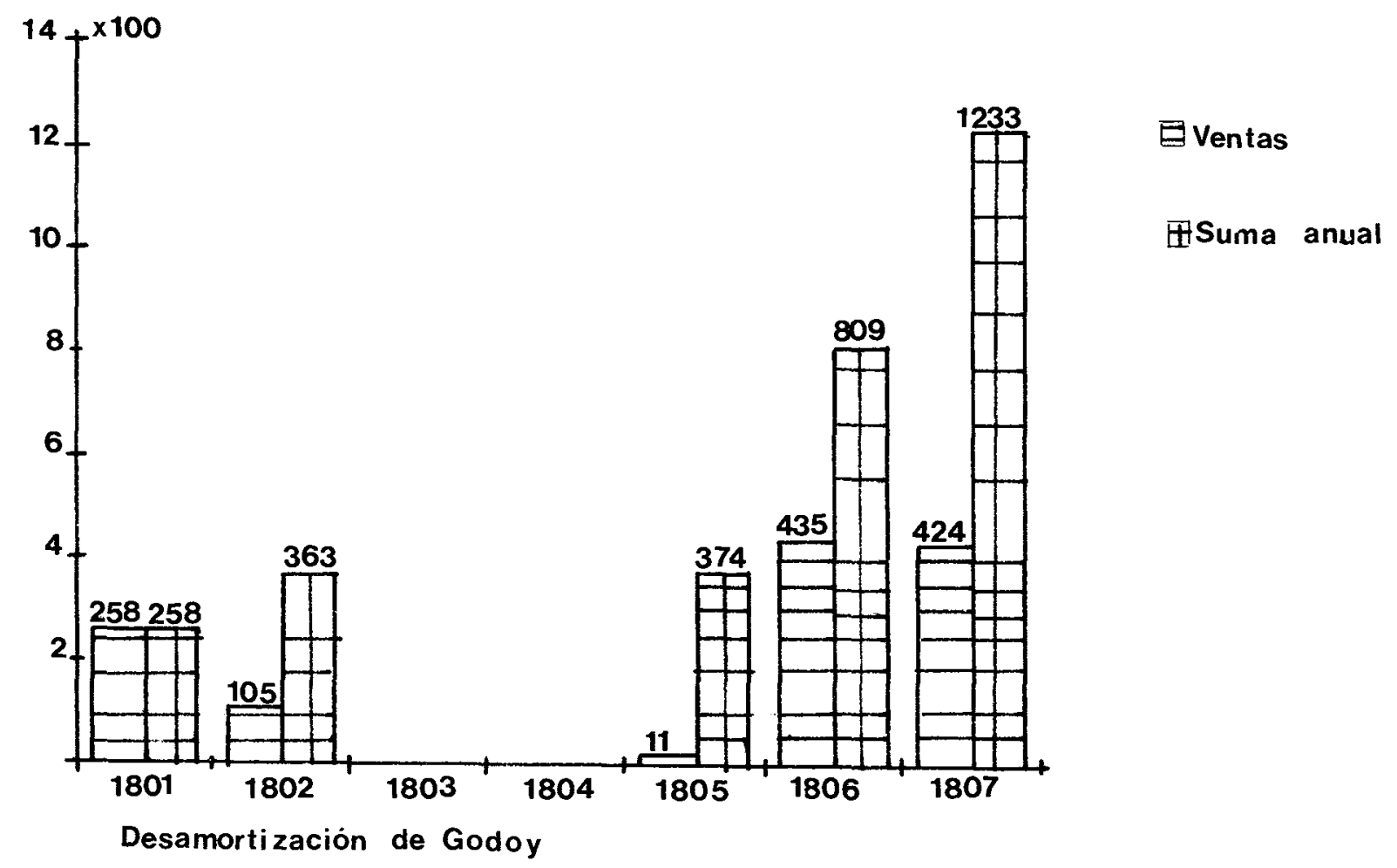




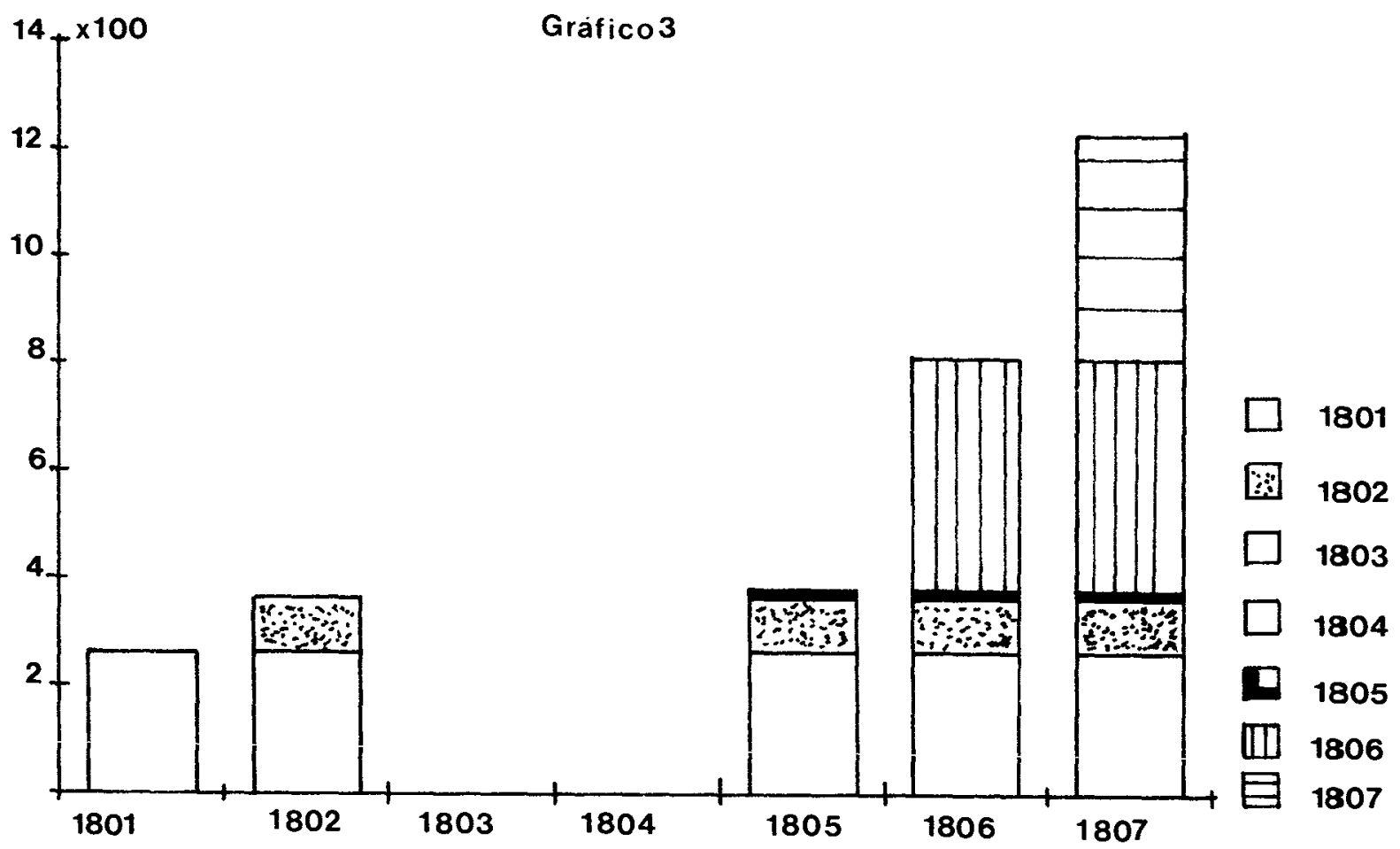

Ventas anuales acumuladas

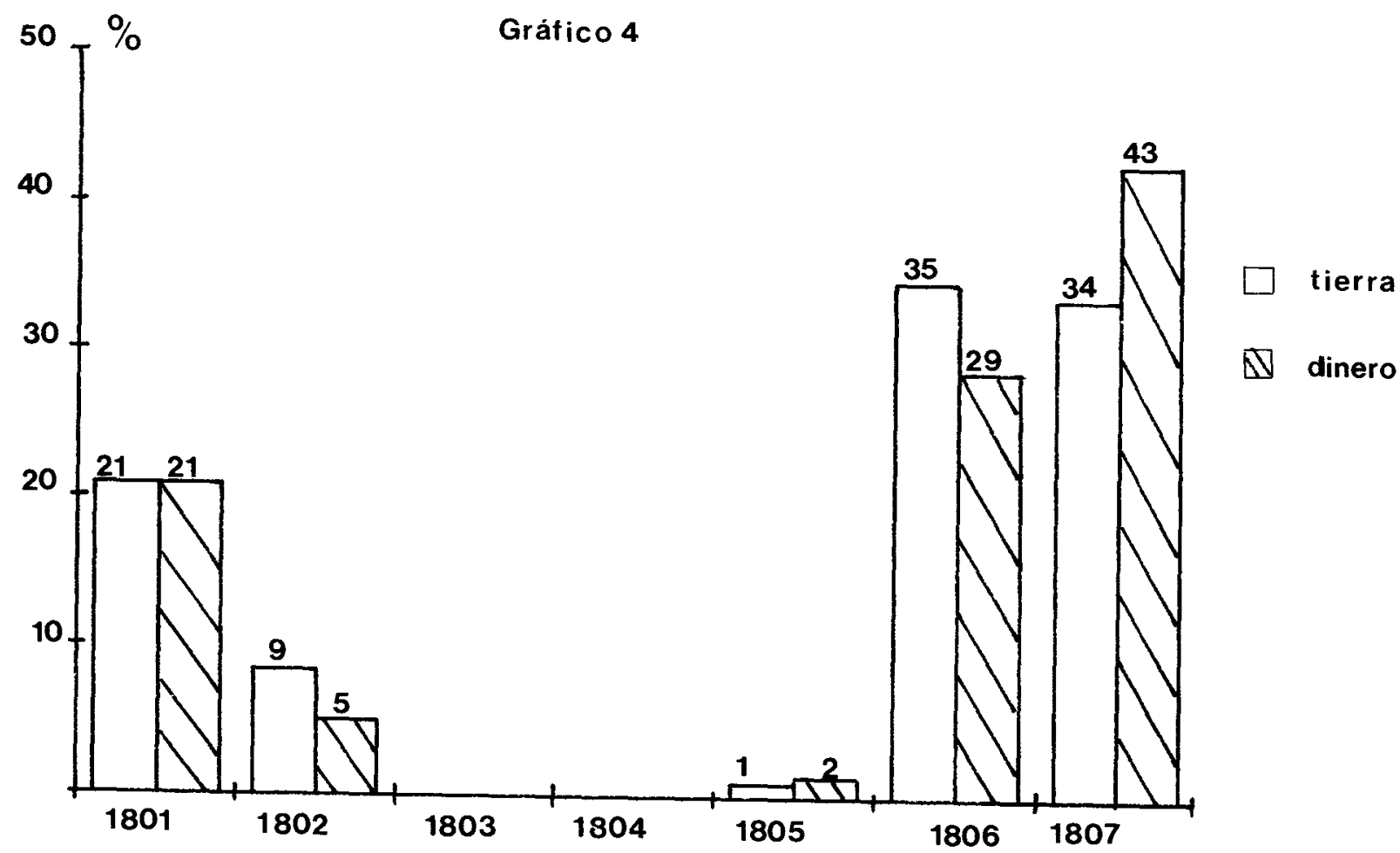

Relación tierra-dinero durante la Desamortización de Godoy 


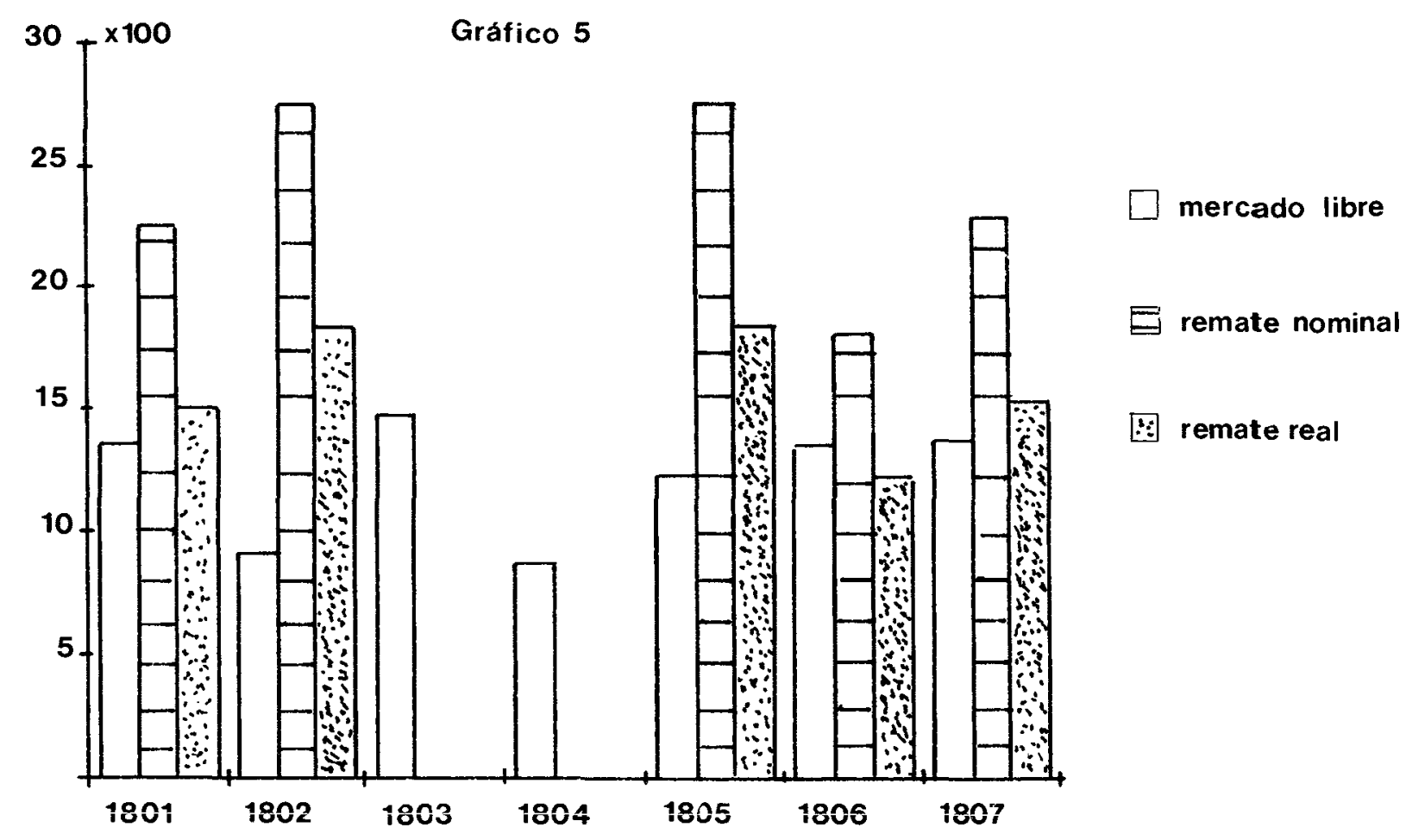

Precio de la fanega de regadio

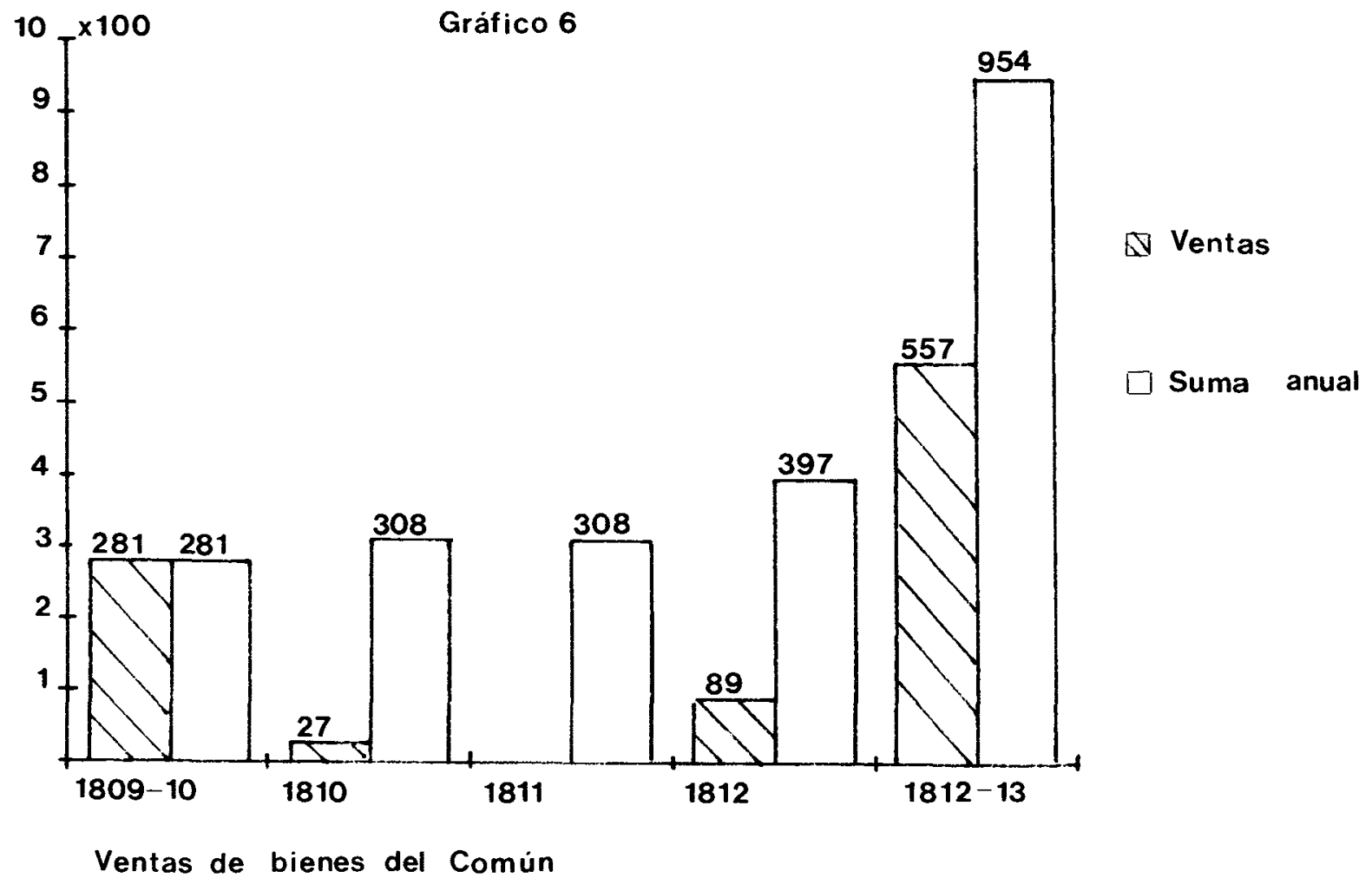



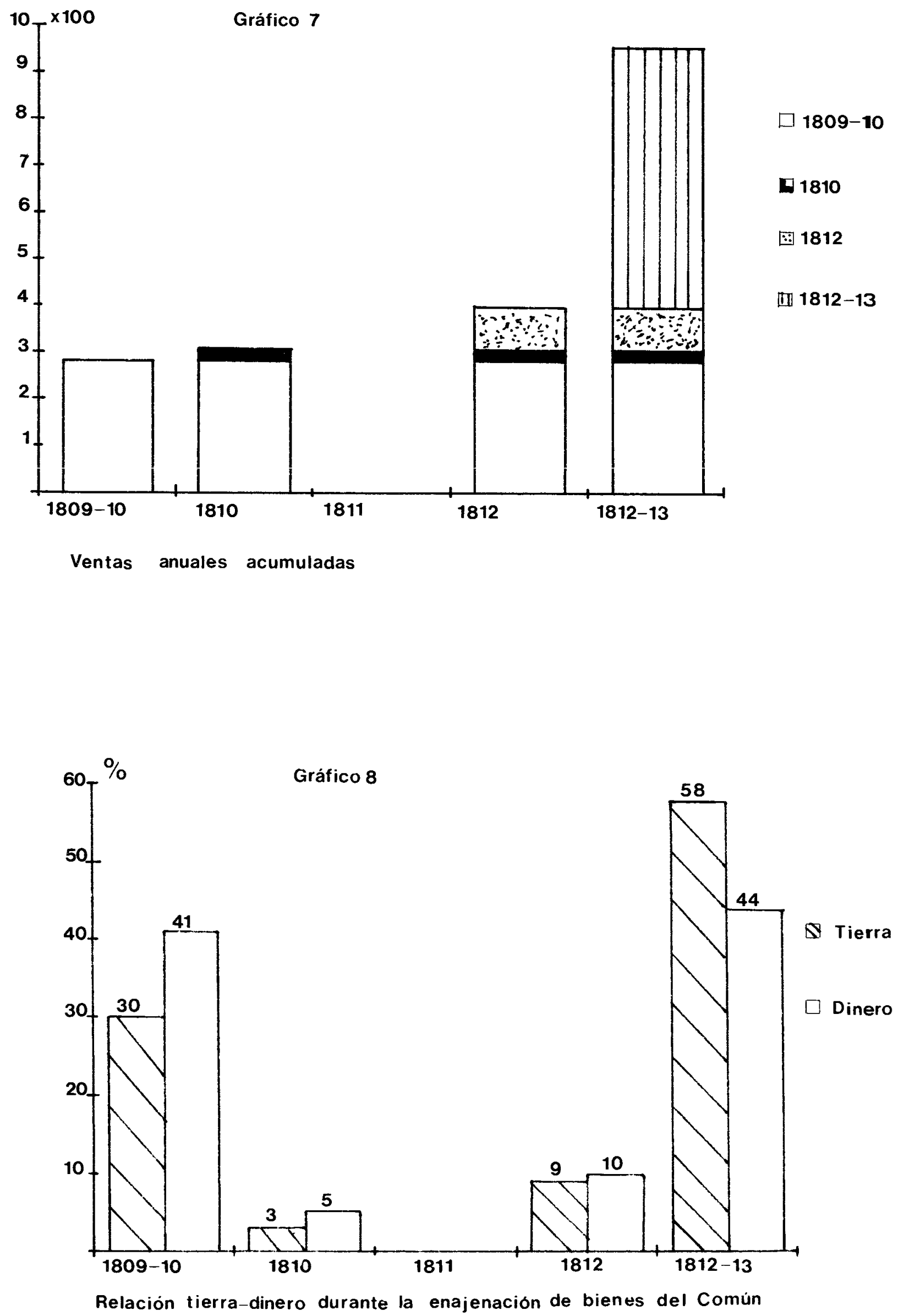
